Cell Research (2002); 12(3-4):177-197

http://www.cell-research.com

\title{
The ATF/CREB site is the key element for transcription of the hu- man RNA methyltransferase like 1 (RNMTL1) gene, a newly discov- ered 17p13.3 gene
}

\author{
JiAn XU, Jing De ZHU*, Min NI, DA FAng WAN*, JiAn Ren GU \\ The State-key Laboratory for Oncogenes and Related Genes, Shanghai Cancer Institute, LN 2200/25, Xie-tu Road, \\ Shanghai 200032, China
}

\begin{abstract}
The human RNA methyltransferase like 1 gene (RNMTL1) is one of thirteen newly discovered genes within a $116 \mathrm{~Kb}$ segment of the chromosome 17p13.3 that suffers from a high frequent loss of heterozygosity in human hepatocellular carcinoma in China[1-5]. To understand the molecular mechanisms underlying transcription control of the RNMTL1 gene in human cancers, we decline using of the conventional approach where the cis-elements bound by the known transcription factors are primary targets, and carried out the systematic analyses to dissect the promoter structure and identify/characterize the key cis-elements that are responsible for its strong expression in cell. The molecular approaches applied included 1, the primer extension for mapping of the transcription starts; 2 , the transient transfection/reporter assays on a large number of deletion and site-specific mutants of the promoter segment for defining the minimal promoter and the crucial elements within; and 3, the electrophoresis mobility shift assay with specific antibodies for reconfirming the nature of the transcription factors and their cognate cis-elements. We have shown that the interaction of an ATF/CREB element (-38 to -31) and its cognate transcription factors play a predominant role in the promoter activity of the RNMTL1 gene. The secondary DNA structures of the ATF/ CREB element play a more vital role in the protein-DNA interaction. Finally, we reported a novel mechanism underlying the YY1 mediated transcription repression, namely, the ATF/CREB dependent transcription-repression by YY1 is executed in absence of its own sequence-specific binding.
\end{abstract}

Key words: $R N M T L 1$ gene, ATF/CREB, YY1, transcription regulation, chromosome 17p13.3.

\section{INTRODUCTION}

Human chromosome 17p13.3 is well known for its association with hepatocarcinoma specific loss of heterozygosity $(\mathrm{LOH})$ at an extremely high frequency

\footnotetext{
* Corresponding author: Tel/Fax: 8621 64224285, E-mail: < zhujingde@yahoo.com > and < nlorg@public.stn.net.cn > Abbreviations used: $\mathrm{LOH}$, loss of heterozygosity; HCC, hepatocellular carcinoma; RNMTL1, RNA methyltransferase like 1; ATF, activating transcription factor; CREB, cAMP-response element binding protein; AP-2, activating protein 2; YY1, Yin Yang-1; RT-PCR, reverse transcription-PCR; VNTR, variable number of repeat; STR, short tandem repeat; SNP, single nucleotide polymorphism; Py, pyrimidine.

Received July-12-2002 Revised July-26-2002 Accepted July-292002
}

[1-5]. In our previous efforts to identify within $17 \mathrm{p} 13.3$ the vital genes, functions of which is to prevent the malignant transformation of the hepatocyte, a $116 \mathrm{~Kb}$ fragment carried by a PAC clone, PAC579, has been fully sequenced and thirteen genes have been cloned by screening the liver cDNA library with the unique sequence within this fragment as probe and gene-mining bioinformatically[6-9]. Purely on the basis of its sequence similarity to a family of the genes well conserved in evolution and encoding the proteins capable of methylating the ribosomal RNA, the gene studied in this report is annotated as the human RNA methyltransferase like 1 ( RNMTL1).

The first level of control over the gene expres- 
sion is concerning with transcription initiation, where both location and frequency of this event were finely modulated[10]. Both availability of the sequence specific transcription factors and accessibility of their cognate sites in chromatin, the real entity of the genome, are the major determinants of whether and how fast the transcription of a given gene should occur. Conventionally, the efforts of depicting the function and elucidating the mechanism underlying expression of any novel gene are initiated from the detailed characterization of the promoter, including mapping the transcription initiation site, delineating the minimal region of the segment with a complete promoter activity, and defining the key cis-elements along with their cognate transcription factors. Following establishing the expression profile of the RNMTL1 gene in context of the tissues and cell lines, we engaged in a set of molecular characterizing maneuvers including bioinformatic analyses, the primer extension practice for mapping starts of transcription, the transient transfection/ reporter assay of both deletion and site-specific mutants of the 5' segment for the promoter activity to identify the minimal promoter region and the crucial cis-elements within, and the electrophoresis mobility shift assay for classification of the sequencespecific protein-DNA interaction of interests. Our data presented in this report would provide the important insights into the transcription regulation of theRNMTL1 gene in particular and enhance our understanding of the general molecular genetic mechanisms applied to a wider range of genes.

\section{MATERIALS AND METHODS}

\section{Cell culture, and transient transfection /reporter gene assays}

SMMC7721 (human hepatocellular carcinoma cell line, Catalogue No. TCHu13), BEL7402 (human hepatocellular carcinoma cell line, Catalogue No. TCHu68), and LO2 (normal human liver cell line, Catalogue No. GNHu6 in Cell Bank of the Chinese Academy of Sciences) were grown at $37^{\circ} \mathrm{C}$ with $5 \% \mathrm{CO}_{2}$ atmosphere in Dulbecco's modified Eagle's medium (DMEM) supplied with 10\% new born bovine serum.

Cultured cells were seeded in a 24 -well plate $\left(5 \times 10^{4}\right.$ cells/well $)$ in $1 \mathrm{ml}$ of complete growth medium and grown to $50 \sim 80 \%$ confluence prior to transfection with a conventional $\mathrm{CaCl}_{2} / \mathrm{phos}$ phate protocol. $1 \mu \mathrm{g}$ each of the promoter-reporter constructs and $0.1 \mu \mathrm{g}$ pRL-TK (Promega, USA) were mixed with $10 \mu 12.5 \mathrm{M}$ $\mathrm{CaCl}_{2}$, and then they were diluted to a total volume of $100 \mu \mathrm{l}$ with the double distilled $\mathrm{H}_{2} \mathrm{O}$. These solutions were dropwise mixed with $100 \mathrm{ml}$ of $2 \times$ Hanks' balanced saline solution and incubated for $15 \mathrm{~min}$ at room temperature. The mixture was added to the cell culture. After $12 \sim 16 \mathrm{~h}$ incubation at $37^{\circ} \mathrm{C}$, the DNA-calcium phosphate complex was washed away with complete medium and cultivated for an additional $24 \mathrm{~h}$ at $37^{\circ} \mathrm{C}$. Cells were thus harvested in $1 \times$ passive lysis buffer (Promega, USA), and both firefly and renilla luciferase activities were measured with a single-tube assay (Dual-luciferase reporter assay system, Promega, USA), in a Lumat luminometer (LB 9506).

To minimize the influence of the unavoidable variation with individual transfection assays, all the experiments were carried out in duplicate. Both the tested promoter fragments that are used to drive the Photimus pyralis (firefly) luciferase gene and the $p R L-T K$ vector (Promega) where Renilla reniformis luciferase is driven by the promoter of the Herpes Simplex Viral thymidine kinase gene were transfected into cells. The luciferase activities of the cell extracts from the recipient cells were quantified by a singletube assay (Dual-luciferase reporter assay system, Promega, USA), and the promoter potency of the tested fragments were presented as the mean and standard deviation of the ratio of the firefly luciferase over the renilla luciferase activity of the duplicates and plotted against the tested constructs. The strength of the promoter was described as ratio of its luciferase activity over that of the control plasmid pGL3-Control where the firefly luciferase gene is under the control of the SV40 early promoter and enhancer (Promega, USA). All the experiments were carried out three times, and the result from one representative experiment was presented.

\section{$R N A$ preparation and expression profiling by a semi-quantitative PCR}

The total RNA was prepared from cultured cells and tissue samples with Trizol reagent according to the manufacturer's instruction (Invitrogen, USA). Then the total RNA was reverse transcribed using oligo (dT) as primer and Superscript $\mathrm{II}^{\mathrm{TM}}$ RNase H-Reverse Transcriptase (Invitrogen, USA). Semi-quantitative PCR was carried out with a pair of primers, each of which resides at different exons of the target gene (Tab 1). The PCR cycling parameters are $94^{\circ} \mathrm{C}$ for $2 \mathrm{~min}$, following by $25-30$ cycles of three steps: $94^{\circ} \mathrm{C}$ for $15 \mathrm{~s}, 60^{\circ} \mathrm{C}$ for $15 \mathrm{~s}$, and $72^{\circ} \mathrm{C}$ for $30 \mathrm{~s}$. The PCR products were separated on a $1.5 \%$ agarose gel and the ethidium bromide stained bands were visualized under UV illumination.

\section{Mapping of the transcription start site(s) by primer extension analysis[11]}

The RNMTL1 specific anti-sense oligonucleotides PE2 5' GGGTCCACCAGCGCCGCCATGTTCCCTGA-3' (+16 to -14, numbering from the initiating ATG) and PE3 5' CGTCACGGGTGGCGCCTTCGTGGACTGG-3' (-53 to -84), were end-labelled with $\left[\gamma_{-}{ }^{32} \mathrm{P}\right] \mathrm{ATP}(\sim 5000 \mathrm{Ci} / \mathrm{mmol})$ using T4 polynucleotide kinase. The labelled primer ( $50 \mathrm{fmol}$ ) was annealed to $10 \mu \mathrm{g}$ RNA in $10 \mu$ l hybridization buffer $(10 \mathrm{mM}$ Tris-Cl pH 6 . $8,1 \mathrm{mM}$ EDTA, $250 \mathrm{mM} \mathrm{KCl}$ ) at $65^{\circ} \mathrm{C}$ for minimal $2 \mathrm{~h}$. Primers were extended with 50 U Superscript $\mathrm{II}^{\mathrm{TM}}$ RNase H-Reverse Transcriptase in a solution containing $250 \mathrm{mM}$ Tris-Cl pH 8.3, $25 \mathrm{mM}$ $\mathrm{MgCl}_{2}, 50 \mathrm{mM}$ dithiothreitol, $1 \mathrm{mM}$ dNTPs, and 10 Units RNase 
inhibitor, for 1 hour at $42^{\circ} \mathrm{C}$. The extended products was chloroform-extracted, ethanol-precipitated, and analyzed by electrophoresis on a $5 \%$ polyacrylamide-urea gel. The size of the extended products was determined by referring to sequencing ladders generated with the same labelled primers on the relevant plasmid DNA templates in a T7 DNA polymerase based manu-sequencing protocol (Amersharm, UK).

Report construct and mutagenesis by the bridgingbased two round-PCR method

A $2.1 \mathrm{~Kb}$ genomic fragment containing the 5'-flanking region of RNMTL1 was subcloned from PAC579, a bacteriophage P1derived artificial chromosomal vector based construct containing $116 \mathrm{~kb}$ insert[7, 9]. Sequencing of both strand of this fragment using vector-specific primers revealed that it contained about 1.5 Kb of the 5' -flanking region of RNMTL1 as well as the translation start codon. A 573 bp fragment upstream of the translation start site was PCR-amplified and subcloned into the promoterless firefly luciferase reporter gene vector pGL3-Basic (Promega) and designated $\mathrm{pF}(-567 /+6) .1$

Progressive 5' or 3' deletions of the promoter segment in $\mathrm{pF}$ were generated using exonuclease III and S1 nuclease (Erase-aBase Kit, Promega). Briefly speaking, pF (-567/+6) DNA was digested with KpnI and MluI, phenol/chloroform-extracted, ethanol-precipitated followed by digestion with exonuclease III for various lengths of time. After digestion by S1 nuclease, the ends were blunted by Klenow fragment in the presence of dNTPs. The blunted and shortened $\mathrm{pF}$ DNA were then circularized by T4 ligase and used to transform the competent DH10B Escherichia coli cells. All deletion mutants were verified by sequencing.

Site-directed mutagenesis of the RNMTL1 minimal promoter fragment was carried out by a bridging-based two round PCR method (the detail protocol will be provided under request). In the first round of PCRs, both 5' and 3' part of segments of the designated replacement mutants, in which 12 or 6 nucleotide sequences were expected to be substituted by EcoRI (GAATTC) and BamHI (GGATCC) or BamHI (GGATCC), were PCR out with two internal primers, the 12 nucleotides of 3 ' part of which are fully complementary to each other. The PCR was performed using $\mathrm{pF}(-567 /+6)$ as template, in a reaction containing $20 \mathrm{pmol}$ of either $\mathrm{mL}$ or $\mathrm{mR}$ flanking primer (Tab 1), 20 pmol of mutagenic primer, $5 \mu \mathrm{l}$ of $10 \times$ buffer, $1 \mu \mathrm{l}$ of $10 \mathrm{mM}$ dNTPs, and 2 Units of Taq polymerase (Promega) in a total volume of $50 \mu \mathrm{l}$. PCR conditions were $94^{\circ} \mathrm{C} 30 \mathrm{~s}, 60^{\circ} \mathrm{C} 30 \mathrm{~s}, 72^{\circ} \mathrm{C} 40 \mathrm{~s}$ for 30 cycles. The PCR products from the first round of PCR were gel purified and quantified. To generate a full-length $914 \mathrm{bp}, 50 \sim 100 \mathrm{ng}$ of left and right overlapping fragments were amplified in a $50 \mathrm{ml}$ reaction solution containing $5 \mathrm{ml}$ of $10 \times$ buffer, $1 \mathrm{ml}$ of $10 \mathrm{mM}$ dNTPs and 2.5 Units of pfu polymerase (Promega) for three rounds (94 ${ }^{\circ} \mathrm{C} 30 \mathrm{~s}, 40^{\circ} \mathrm{C} 30 \mathrm{~s}, 72^{\circ} \mathrm{C} 1 \mathrm{~min}$ ) without any primers. Then $20 \mathrm{pmol}$ of $\mathrm{mL}$ and $\mathrm{mR}$ flanking primers were added into the reaction before PCR for another 25 cycles at $94^{\circ} \mathrm{C} 30 \mathrm{~s}, 55^{\circ} \mathrm{C} 30 \mathrm{~s}, 72^{\circ} \mathrm{C} 30$ s. After ethanol precipitation, the PCR products were restricted with SacI and HindIII and cloned at the same sites of the pGL3Basic vector to create the report constructs with designated sequence replacement. All the mutants were verified by sequencing.

\section{Electrophoresis mobility shift assay[12]}

Nuclear extracts were prepared from cultured cells by a modified protocol of the Dygnan[13]. Two complementary strands of the oligonucleotides at an equal molar input were 5' kinase labelled with $\left[\gamma-{ }^{32} \mathrm{P}\right] \mathrm{ATP}(\sim 5000 \mathrm{Ci} / \mathrm{mmol})$ as previously described. After heat-inactivating the kinase at $65^{\circ} \mathrm{C}$ for $5 \mathrm{~min}, \mathrm{NaCl}$ was added into the reaction to a final concentration of $0.1 \mathrm{M}$. The reannealling process to form double-stranded oligonucleotide molecule was carried out by gradual reduction of temperature for $2 \mathrm{~h}$. Then the protruding ends of the double-stranded oligonucleotide molecule were polished by $37^{\circ} \mathrm{C}$ incubation with Klenow fragment in the presence of dNTPs. Three oligonucleotides were used for this study: CE (5' -CCGTGACGTCACTAGCCGCCGACGGCGCGC3' ), CE1 (5' -CCGTGACGTCACTAGC-3' ) and CE2 (5' CGCCGACGGCGCGC-3' ) [Only the top strand sequence is presented]. $5 \mu \mathrm{g}$ of the protein extract was incubated on icefor 20 min with $10 \mathrm{fmol}$ of ${ }^{32} \mathrm{P}$-end-labelled oligonucleotides, in a $20 \mu \mathrm{l}$ solution containing $1 \mathrm{mg}$ poly dI:dC (Pharmacia), $12.5 \mathrm{mM}$ Herpes,

Tab 1. Oligonucleotides used in PCR

\begin{tabular}{lccc}
\hline Oligonucleotid & \multicolumn{1}{c}{ Sequence $\left(5^{\prime} \rightarrow 3^{\prime}\right)$} & Product size & GenBank No. \\
\hline $\begin{array}{l}\text { RNMTL1-L } \\
\text { RNMTL1-R }\end{array}$ & $\begin{array}{l}\text { CCAGGAGCAACGAGAGAAAC } \\
\text { GCTTATCGACTGGCAACTCC }\end{array}$ & $278 \mathrm{bp}$ & AF177344 \\
\hline YY1-L & $\begin{array}{l}\text { CTGGCATTGACCTCTCAG } \\
\text { CTGAAAGGGCTTCTCTCC }\end{array}$ & $266 \mathrm{bp}$ & XM-007245 \\
\hline CREB-L & $\begin{array}{l}\text { GGCCTGCAAACATTAACCAT } \\
\text { CREB-R }\end{array}$ & \multirow{2}{*}{$297 \mathrm{bp}$} & NM-004379 \\
$\beta$-actin-L & AAGTACTCCGTGTGGATCGG & \multirow{2}{*}{$616 \mathrm{bp}$} & X00351 \\
$\beta$-actin-R & TCAAGTTGGGGGACAAAAAG & & \\
\hline $\mathrm{mL}$ & CGGTAGACGGTAAGCTCCAC & $214 \mathrm{bp}$ & $/$ \\
$\mathrm{mR}$ & GAAACGAACACCACGGTAGG & & \\
\hline
\end{tabular}


$\mathrm{pH} 7.9,6.25 \mathrm{mM} \mathrm{MgCl} 2,50 \mathrm{mM} \mathrm{KCl}$ and $10 \%$ glycerol. The DNAproteincomplexes were analyzed in a cold room $\left(\sim 7^{\circ} \mathrm{C}\right)$ by electrophoresis on a non-denaturing $4 \%$ polyacrylamide gel with $0.5 \times$ TBE as running buffer (1×TBE: $89 \mathrm{~m} M$ Tris, $89 \mathrm{~m} M$ boric acid, 8 $\mathrm{m} M$ EDTA, pH 8.0). $20 \sim 100$ fold molar excess of the individual double-stranded oligonecleotides were included in the binding reaction for both specific and non-specific competition analyses. For supershift experiments, $2 \mu \mathrm{g}$ of specific antibodies: CREB1 (C21), a polyclonal antibody to ATF2 (N-96), and monoclonal antibody against YY1 (H-10) (Santa Cruz Biotechnology, USA) were added prior to the addition of radiolabelled probe. After electrophoresis, the gels were dried onto DEAE paper (Whatman DE81) before autoradiography was taken.

To evaluate methylated CpG effects on the protein-DNA binding, the reannealled double-stranded oligonucleotide $\mathrm{CE}\left({ }^{32} \mathrm{P}-\right.$ labelled and cold) was methylated by SssI methylase in presence of S-adenosyl methionine (NEB, Boston, USA). The rest steps were carried out as above.

\section{RESULTS}

\section{Expression profile}

The region showing a high frequent loss of heterozygosity in tumors identified by comparing the tumor samples with the matched non-cancerous tissues for the occurrence of the molecular genetic markers (VNTR, STR and SNP, etc.) may have the genes possessing the tumor suppression function resided in. Therefore, as the first step of study, once this newly discovered gene was identified and cloned, we experimentally established the expression profile of the RNMTL1 in the context of both tissues from the hepatocarcinoma patients and the established cell lines that would be used as the recipient cells in the further study. With the $\beta$ - actin as the cDNA loading control and the PCR reactions for a limited numbers of cycles, we analyzed nine established cell lines and four pairs of patients' tissues along with two normal liver tissues. As shown in Fig 1 , no significant difference in the density of the PCR band was observed among different samples. This indicates that the RNMTL1 gene does not have the hepatocellular carcinoma specific pattern of expression, at least, at the level of transcription. If it plays any role in the hepatocellular carcinogenesis, other levels of the controls, such as those at the levels of translation or post-translation, may be involved.

Mapping of the transcriptions start site(s) of the human RNMTL1 gene by primer extension analysis

The first crucial information to the downstream boundary of the promoter of any given gene is con- cerning where the transcription is initiated. The previous efforts to clone the full-length RNMTL1 cDNA resulted in a number of clones with various 5 ' ends (unpublished observations). Although the initiation sites may be predicted based on the statistic survey of an increasing number of the genes experimentally studied[10], the definite conclusion of any newly discovered gene has to be drawn from the experimental characterization. To this end, the primer extension stands out with both simplicity and efficiency among all approaches, in which the' ${ }^{32} \mathrm{P}$ end-labelled gene-specific anti-sense oligonucleotides are used as primers for the reverse transcription of the RNA template. The resulted 5' endlabelled cDNAs were separated in the denatured polyacrylamide sequencing gel and the length of the labelled cDNA fragments should in principle reflect

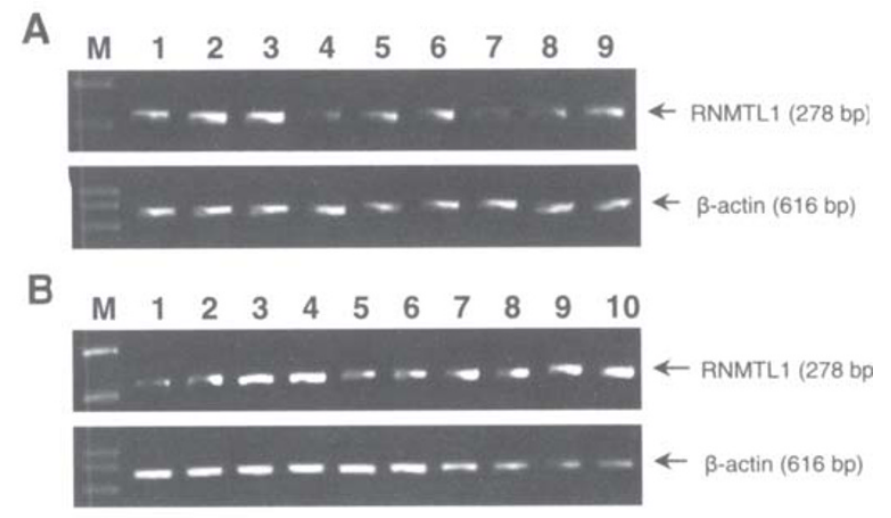

Fig 1. The RNMTL1 expression profile Total RNA from cultured cells and tissues were isolated and RT-PCR was performed using $\beta$-actin as an internal control. A, Lane 1-9, LO2, SMMC7721, BEL7402, U2OS, C33A, Hela, HEK293, PMHO8910, SKOV3 cells. B, Lane 1-2, normal human livers, lane 3-4, D15N and D15C, lane 5-6, D24N and D24C, lane 78, G62N and G62C, lane 9-10, Q80N and Q80C. "C" indicates HCC samples while "N" indicates adjacent non-cancerous liver tissues.

the 5' end of primary transcripts of the gene being studied. We performed primer extension analyses with two complementary oligonucleotide probe PE2 ( +16 to -24 , numbering from the initiation ATG) and PE3 (-53 to -84) (Fig 2B). As shown in the Fig 2 , panel $\mathrm{A}$ and $\mathrm{C}$, we found four distinct extended products from total RNA of the normal liver tissues, LO2, SMMC7721 and BEL7402 cells in experiments where PE2 primer was used. In order to map the initiation site precisely, the sequencing ladders made with the same labelled primers and the plasmid DNA 
containing the relevant insert as template were run in parallel. Therefore, we can confidently conclude that there were four starts in all the cells tested for the RNMTL1 gene transcripts. The downstream two are at $\mathrm{CA}$, where $\mathrm{A}$ is numbered as +1 , and the other two are at $\mathrm{C}$ and $\mathrm{A}$ located at -19 and -20 away from the A (+1), respectively. As indicated below (Fig 3), this promoter lacks both TATA and CCAAT boxes. The genes of this category are characteristic with a short piece of consensus sequence (the initiator: Py Py A N T/A Py Py, where A is the +1), embracing the transcription starts[10]. After the starts of transcription were mapped (Fig 2A-C), the startembeded sequences were aligned with the consensus of the initiator (Fig 2D). Except for that the role for the +3 nucleotide where it should be either $\mathrm{T}$ or A in the consensus is violated in both start-embeding segments, the principles for the rest six nucleotides in this consensus are well complied[10]. However, as the $\mathrm{A}$ or $\mathrm{T}$ at the +3 position has been claimed crucial, whether the transcription starts of the RNMTL1 gene fall into the category of the orthodox initiator containing genes remains to be investigated.
As no extended product was detected in experiments with probe PE3 as primer (data not shown), we concluded that the RNMTL1 gene does not utilize any further upstream starts other than the four identified for transcription (Fig 2).

Bioinfomatic analysis of the 5'-flanking region of the human RNMTL1 gene

After determining the transcription initiation sites, we analyzed the upstream region having its 5' end extending to $1.5 \mathrm{~Kb}$ with the TRANSFAC 4.0 [14], a prediction software for the DNA motifs recognized by the known transcription factors. As shown in Fig 3, there is a GC rich region falling into the category of the $\mathrm{CpG}$ island[15]. There are no classic TATA and CCAAT boxes near the transcription start site of the RNMTL1 gene, a solid indication for the TATA-less gene[10]. A number of consensus sequences are present, recognized by the known transcription factors such as three E2FDPconsensus sites, one ATF/CREB consensus site, three AP-2 sites and several SP1 sites in this promoter (Fig 3, A and B). However, the computer pre-

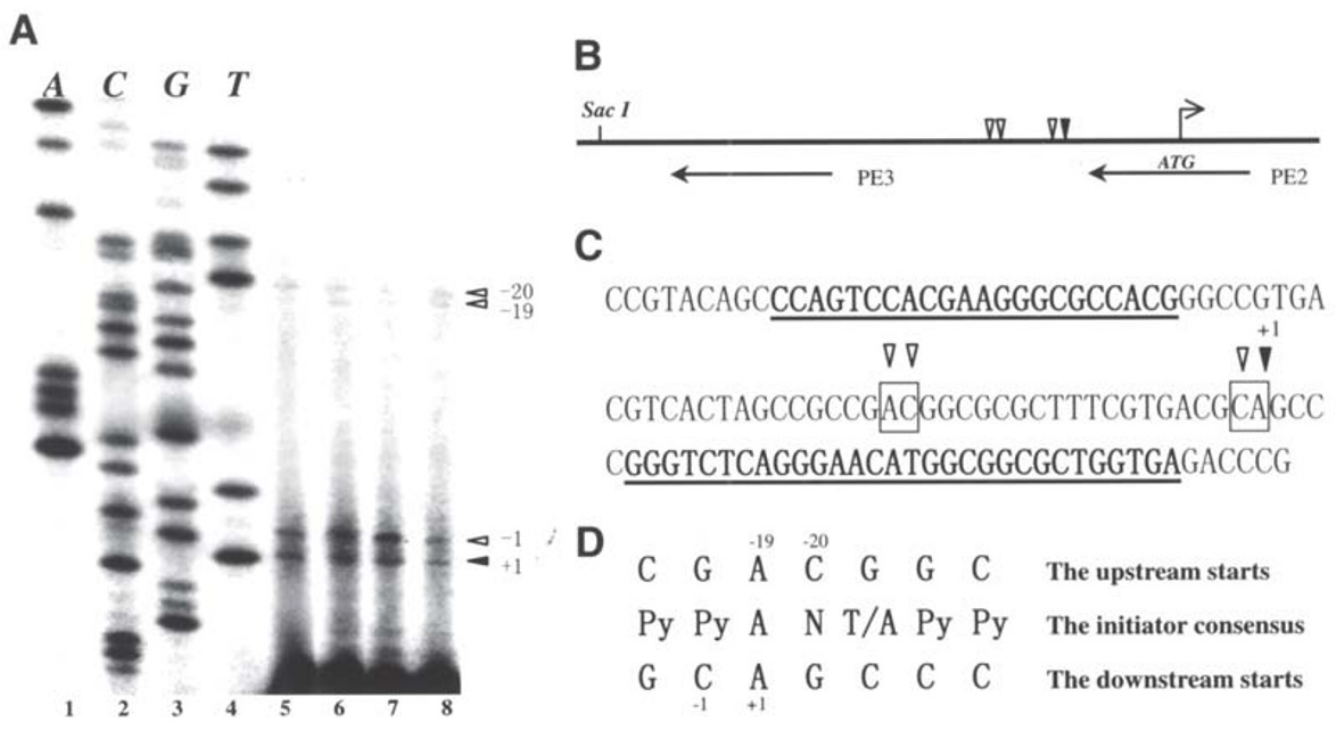

Fig 2. Mapping the start sites by primer extension $\quad \mathbf{A}$, The primer extension mapping of the RNMTL1 initiation site using ${ }^{32} \mathrm{P}$-labelled oligonucleotide PE2. Lane 1-4, the nucleotide of the sequencing reaction using primer PE2 and a genomic fragment; lane 5, primer extension reaction with $10 \mu \mathrm{g}$ total RNA from the tissue sample of normal human liver; lane 6-8, primer extension reaction with $10 \mu \mathrm{g}$ total RNA from LO2, SMMC7721 and BEL7402 cell lines. The primer-extended products are indicated by black arrowhead (major start) and light arrowheads (minor starts). B, Schematic illustration of the relevant positions of the primers to the templates. $\quad \mathbf{C}$, The location of the major initiation site is marked as position +1 and the oligonucleotides used for primer extension analysis are underlined. D, The alignment of both downstream starts and upstream starts with the initiator consensus sequence (the central line). The initiation starts are indicated along with the relevant locations. 
diction is largely based upon the experimental data obtained from the in vitro binding assay, and frequently over-estimates the significance of the sequence similarity. Whether these sites do have the functional significance remains to be experimentally determined.
The minimal promoter region of the human RNMTL1 gene is a 72 bp fragment extending from -71 to +1

To evaluate the promoter activity in cells, the common and efficient approach is to transfect the constructs, in which the reporter gene such as firefly luciferase gene is at the downstream of the tested DNA fragment, into the cells and assess the reporter

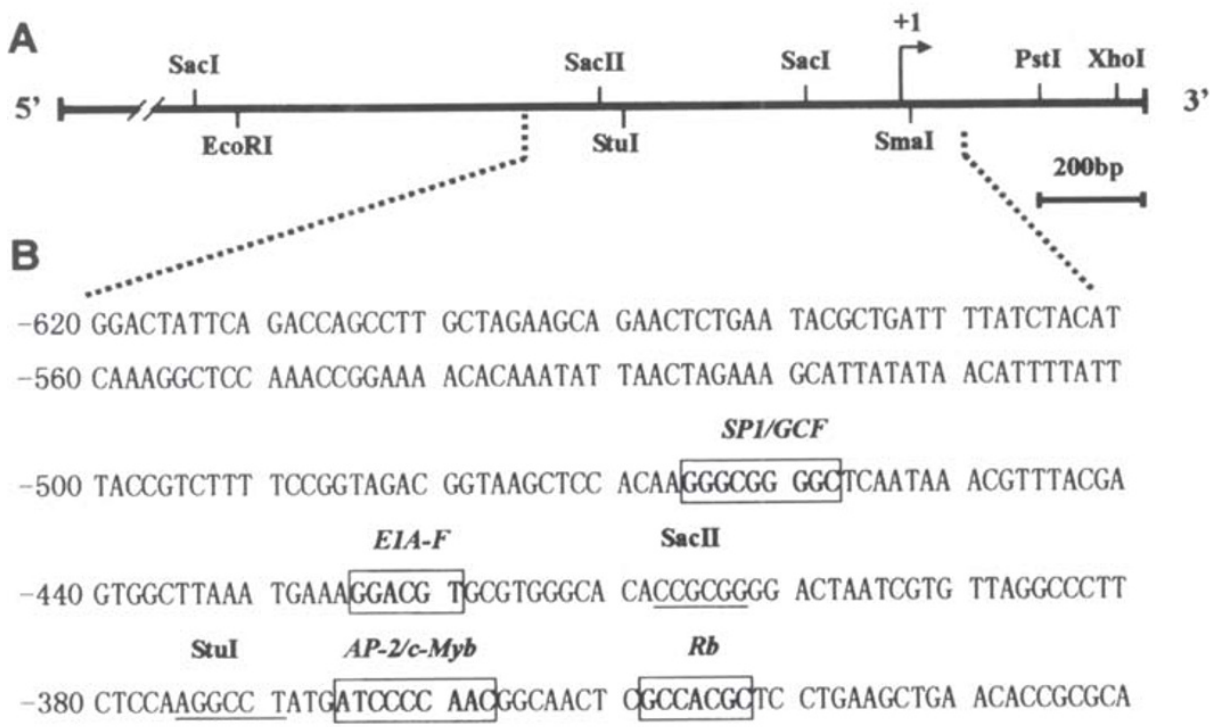

-320 GGGCCTAAGG TCGGACACCC TCCGGCTTAG GTTCACGACA CACCCATTTT CCCCTCCCTC

$\begin{array}{ccc}\text { E2F-DP } & \boldsymbol{A P - 2 / S P 1} & \boldsymbol{A P - 2} \\ -260 \text { CGCCAGGGCC GGCTCGGGOG OOGGTTCCAG CCTCGCGOGC CAGCOCCTGT CGGOCOCGG }\end{array}$

E2F-DP/SPI

-200 CTGCACCTTC ATCCCCAGGA CGTCCCGATA GAAACGCGCC GTCTGGAAGC GGTTTCCCAC

SacI (-123 to -117) SPI

-140 TTtGaATACG AagTGCAGAG CTCTGCGAGC AGCCATGATT CCCGCOGCAC GCAGCCGTCA

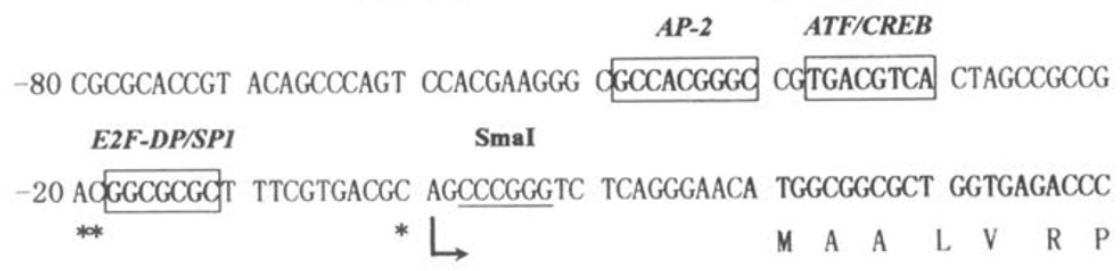

+40 GCGAGGTTTGTCGTGOGACOGTTGCTG..

$\begin{array}{llllllllllllll}\text { A } & R & F & V & V & R & P & \text { L } & \text { L }\end{array}$

Fig 3. The primary structure of the human $R N M T L 1$ gene romoter A, A partial restriction map of a 2.1 $\mathrm{Kb}$ genomic fragment containing the 5' -flanking region of RNMTL1. B, Nucleotide sequence (-620 to +69) of the genomic region surrounding the transcription starts (the major start +1 is indicated by a curved arrow) while the other three start sites at -1, -19 and -20 are indicated by asterisk). Potential cis-acting elements are indicated by box and discussed under "Result". Nucleotides indicated in boldface are coding sequences of the RNMTL1 gene. 
protein activity in the cell extract after a couple of days' culture. To start with our functional analysis, a $573 \mathrm{bp}$ fragment covering from -567 to +6 region of the RNMTL1 gene was PCR cloned to the 5' end of the firefly luciferase gene in the pGL3-Basic vector, and designated $\mathrm{pF}$. After confirming its promoter activity as powerful as the SV40 early promoter plus enhancer in pGL3-Control in the transfected cells, we made and tested a series of deletion mutants either from 5' or 3' ends of this fragment in $\mathrm{pF}$. The deletion from 5 ' end to as much as -71 in pD8 $(-71 /+6)$ construct did not significantly affect the potency of the promoter activity in the transfected SMMC 7721 cells (Fig 4). As the 3' boundary of the promoter was fairly precisely predictedby taking the start of transcription (Fig 3) as reference, we started with nucleotide at +6 as its 3 ' end. As shown in Fig 4, while the segment in pD9 (-201/ +1 ) maintains a full strength of promoter activity, a removal of 3 base pairs more from 3 ' end of promoter segment represented by pD10(-201/-3) resulted in approximately $40 \%$ reduction of the promoter activity. A further removal of $15 \mathrm{bp}$, represented in pD11(-201/-18), the promoter activity was completely abolished (Fig 4). Despite of the fact that the two upstream starts (-19 and -20$)$ remain in pD11, its loss of the promoter activity may not conclude that these two upstream sites do not have significantly functional role in vivo. Based on the data in Fig 4, the minimal promoter of the RNMTL1 gene is, thus, extending from -71 to +1 and $72 \mathrm{bp}$ in length.

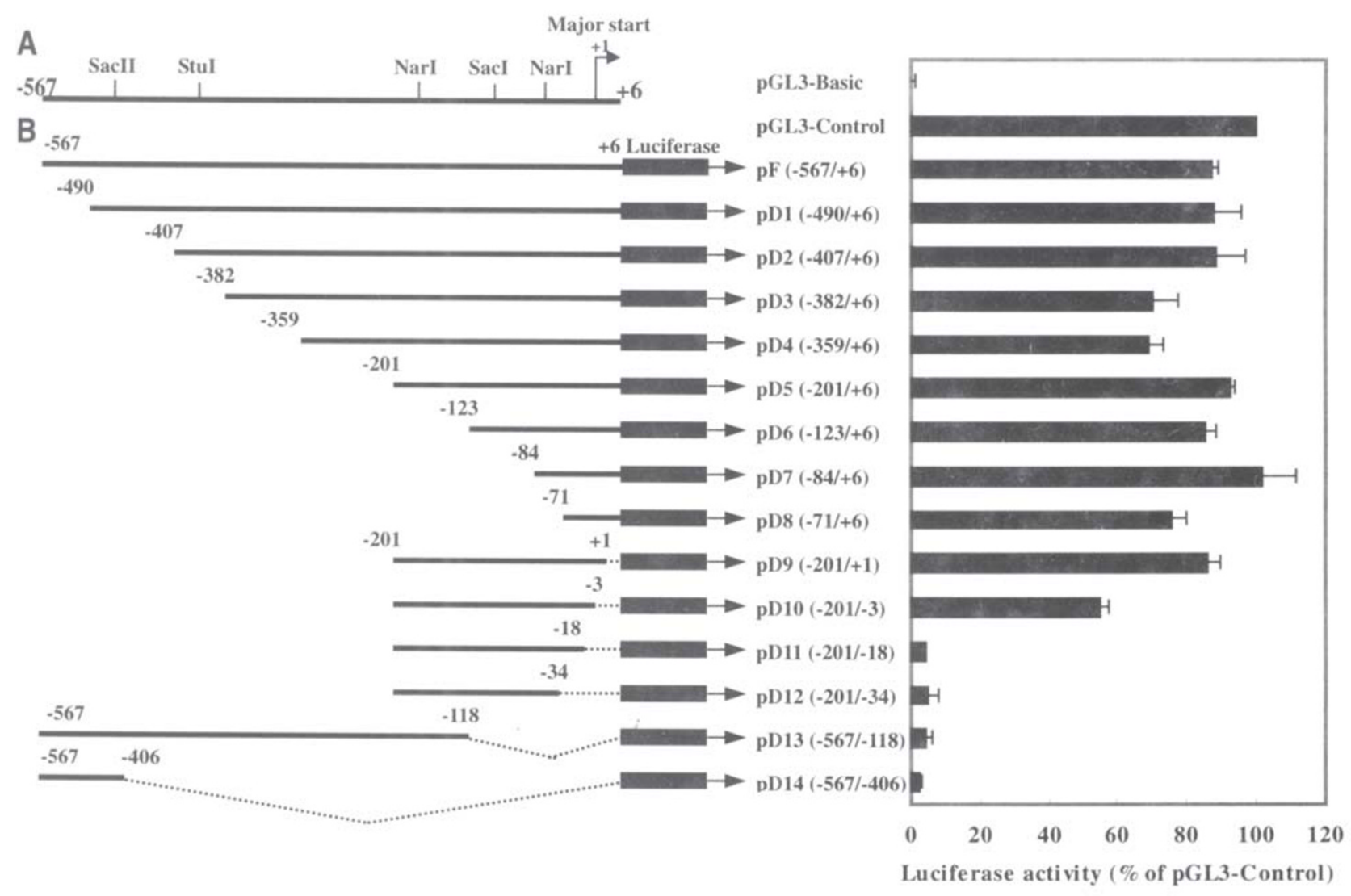

Fig 4. Deletion mapping of the RNMTL1 minimal promoter A, A partial restriction map of the RNMTL1 promoter $(-567$ to +6$)$. The bent arrow indicates the major start site. $\quad \mathbf{B}$, Schematic illustration of the RNMTL1 reporter constructs used in transient transfection analysis of promoter activity in SMMC7721 cell line. Thin lines indicate vector sequences; black bars indicate luciferase reporter gene, and thick lines indicate the RNMTL1 promoter fragments. Positions relative to the transcription initiation site are indicated. The promoter-reporter constructs were co-transfected with a control plasmid (pRL-TK) and assayed $24 \mathrm{~h}$ later. The results are the mean \pm S.D. of duplicate from one of three separate experiments and are shown as percentage of activity of pGL3-Control (see the relevant section in Materials and Methods). 
Identifying the crucial cis-elements by analyzing the promoter activity of a set of mutants, each of which has 12 nucleotide sequences altered by the bridgingbased two round PCR method

The bioinformatic analyses revealed quite a few sequence motifs, respectively recognized by the known transcriptional regulators, namely, one AP2 site ( -49 to -41$)$, one ATF/CREB site (-38 to -31$)$ and one E2F-DP/SP1 site (-18 to -12$)$ within the minimal promoter (Fig 5A). Among them, the ATF/ CREB site is $100 \%$ homologous with the consensus (the expectedvalue: 10-3)[16], while other two deviate significantly from the consensus (the expected value $10^{-1}$ ) of the database[14]. The questions as to which of these sites have any functional relevance and are there any novel sites, interaction of which with their cognate transcription factors may contribute to the promoter activity of the minimal promoter of the RNMTL1 gene, can only be addressed by experimentation. To this end, one may focus one's attention to those sequences potentially bound by the known transcription factors. Instead, we adopted
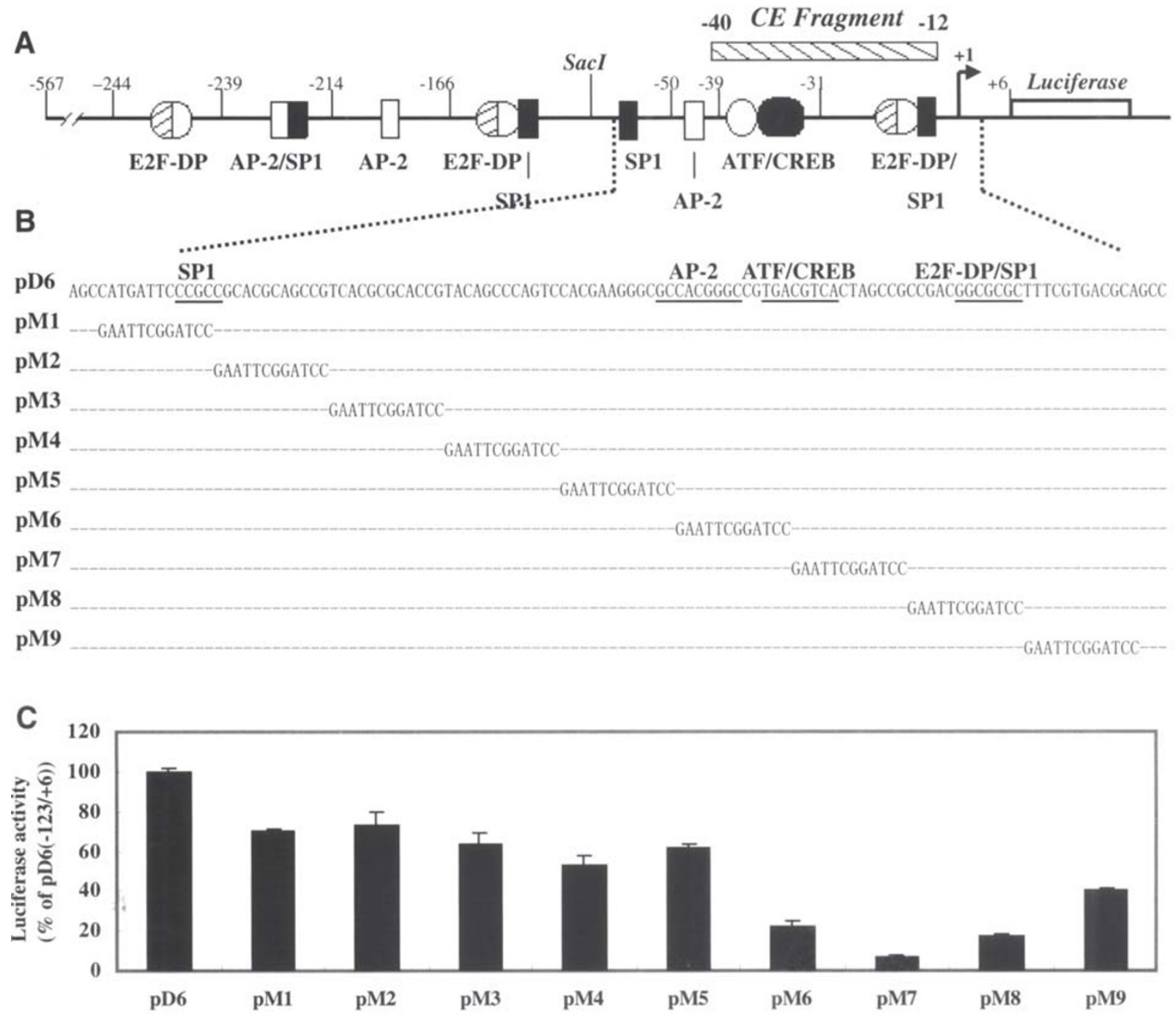

Fig 5. The promoter activity of the sequence replacement mutants of the RNMTL1 minimal promoter A, A partial map of the cis-elements recognized by the prediction software. CE fragment designates the nucleotide used in EMSA. B, The alignment of the mutated sequence in each 12 nucleotide replacement mutants over the wild-type, pD6(-123/+6) in Fig 4. C, The luciferase activity of each mutants in SMMC7721 cells is presented as the mean 了S.D. of duplicate samples from one of three separate experiments by taking the promoter activity of $\mathrm{pD} 6(-123 /+6)$ as reference. 


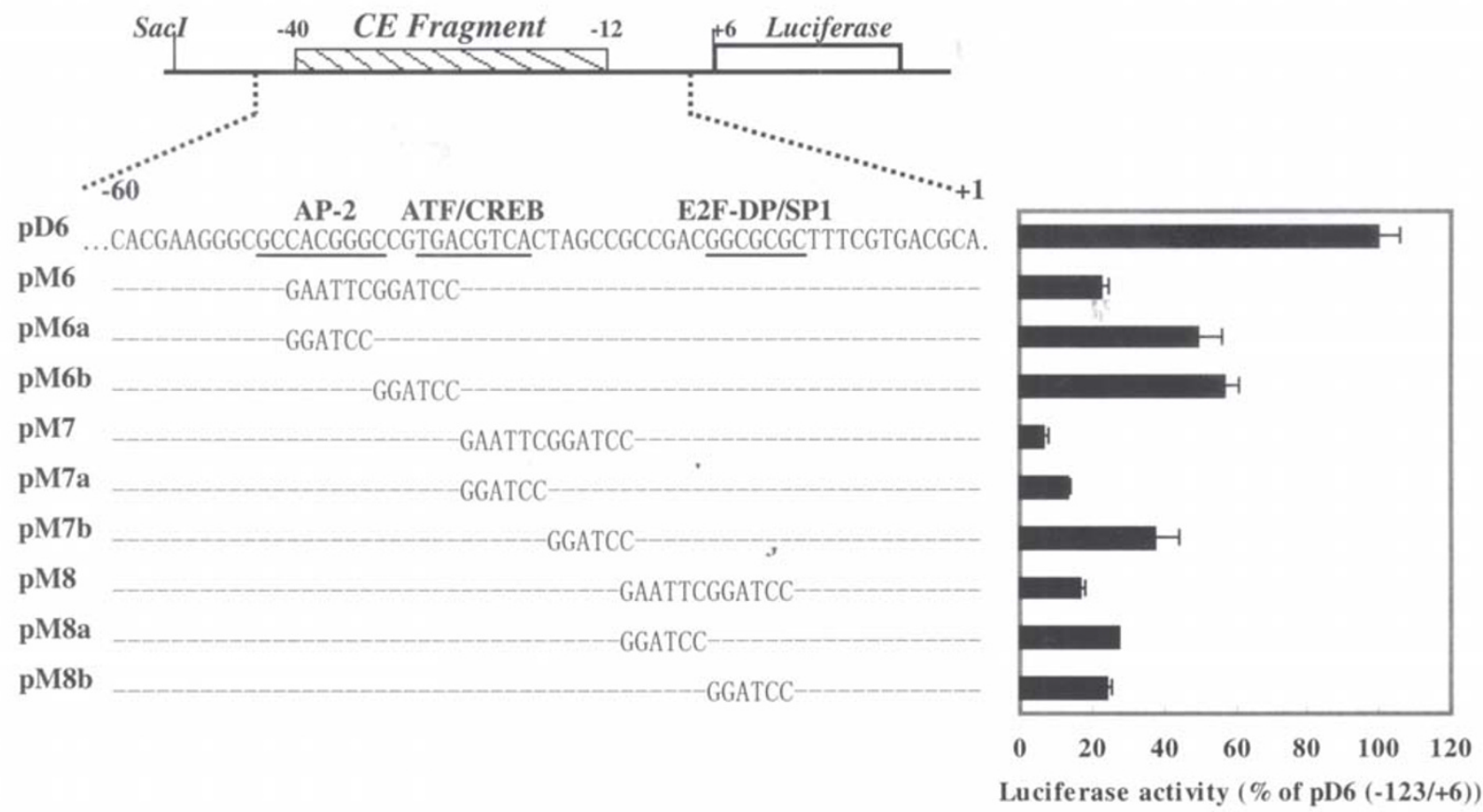

Fig 6. The promoter activity of the sequence replacement mutants (6 bp each in CE fragment) of the RNMTL1 minimal promoter The nucleotide sequences of three functionally important cis-acting elements are underlined. The nucleotide sequences of $6 \mathrm{bp}$ linkers are listed and the original sequences are shown as hyphens. The luciferase activity of each mutant in SMMC7721 cells is presented as the mean \pm S.D. of duplicate samples from one of three separate experiments by taking the promoter activity of pD6(-123/+6) as reference.

A

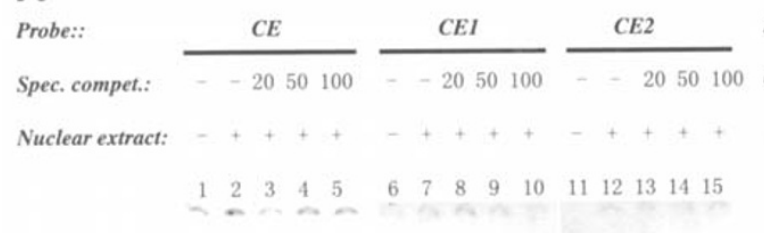

B

Competitor $(50 \times)$ :

Nuclear extract:
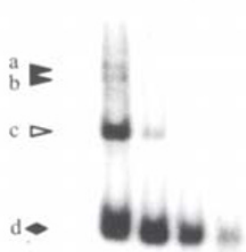

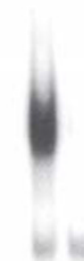

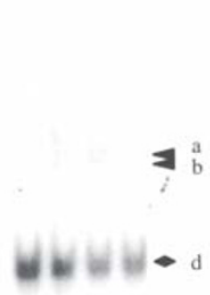

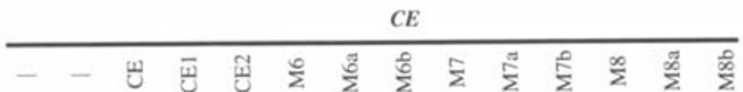

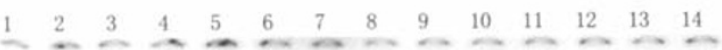

Fig 7. DNA-protein interactions revealed by electrophoresis mobility shift assay $\quad$ A, $5 \mu \mathrm{g}$ SMMC7721 nuclear extracts were incubated with the ${ }^{32} \mathrm{P}$-labelled double-stranded oligonucleotides CE (position -40 to -12 , lane 1-5), CE1 (position -40 to -26, lane 6-10) and CE2 (position - 25 to -12, lane 11-15) with or without 20-100 fold molar excess of specific competitor. B, The effects of the mutation on the CE fragment specific DNA-protein interactions. The formation of DNA-protein complexes were competed with 50-fold molar excess of CE as well as various CE mutants in the form of double-stranded oligonucleotides (listed above lane 3-14, for sequences, see Tab 2), and analyzed by EMSA in the 4\% polyacrylamide gels. The black arrowheads (a, b) indicate ATF/CREB site-specific complexes. The light arrowhead (c) indicates E2F-DP/SP1 site-specific complexes and the black diamond (d) indicates nonspecific complexes. 
an alternative, i.e., a systematicalapproach by testing a set of the mutants. In each of 9 mutants in the context of a short promoter $(-137$ to +1$)$, every 12 nucleotides of the insert were sequentially replaced with the following sequence: EcoRI (GAATTC) and BamHI (GGATCC) restriction enzyme sites that lack any known cis-elements (Fig 5B). While all of the mutants have the reduced promoter activity to various extents (Fig 5C), the alteration of the sequence represented by the mutants, $\mathrm{pM} 6, \mathrm{pM} 7$ or $\mathrm{pM} 8$, are most detrimental. Only $23 \%, 7 \%$ and $17 \%$ of the wild type activity remained, respectively. Coincidentally, the changes in pM6, pM7 and pM8 mutants disrupted the following three cis-acting elements: AP-2 site (-49 to -41), ATF/CREB site (38 to -31$)$ and E2F-DP/SP1 site (-18 to -12$)$ along with the two upstream transcription start sites, respectively.

To further map the crucial sequence within this 36 base pair fragment, which was affected partially in pM6, pM7 and pM8 constructs, additional six mutants were made and tested in the transient transfection/reporter assay, in each of which only 6 bp sequence was replaced by the BamHI restriction site (Fig 6). The lowest promoter activity (17\% of the wild type) was observed in the mutant pM7a

Tab 2. Oligonucleotides used in EMSA

\begin{tabular}{|c|c|c|}
\hline & Oligonucleotides & Sequence $\left(5^{\prime} \rightarrow 3^{\prime}\right)$ \\
\hline \multirow{5}{*}{$\begin{array}{l}\text { مे } \\
\text { 는 }\end{array}$} & $\mathrm{CE}^{\bullet}$ & CCGTGACGTCACTAGCCGCCGACGGCGCGC \\
\hline & CE1 & CCGTGACGTCACTAGC \\
\hline & CE2 & CGCCGACGGCGCGC \\
\hline & $\mathrm{CE}_{3}{ }^{*}$ & CCGTGACGTCACTAGCCGCCGACGGCGCGC \\
\hline & $\mathrm{CE}^{\mathrm{m}}{ }^{-\infty}$ & COGTGACGTCACTAGC \\
\hline \multirow{15}{*}{ 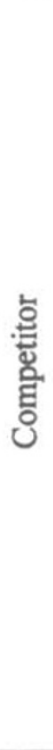 } & M6 & gaat tcggatcc CGTCACTAGCCGCCGA \\
\hline & M6a & ggatccCCGTGACGTCACTAGCCG \\
\hline & M6b & CACGGGggatccCGTCACTAGCCGCCGA \\
\hline & M7 & CACGGGCCGTGAgaat tcggatccCCGACGGCGCGCTTTC \\
\hline & M7a & CACGGGCCGTGAggatccTAGCCGCCGACGGCGCG \\
\hline & M7b & CACGGGCCGTGACGTCACggatccCCGACGGCGCGCTTTC \\
\hline & M8 & CGTGACGTCACTAGCCGgaat tcggatccTTTC \\
\hline & M8a & CGTGACGTCACTAGCCGgaat teGCGCGCTTTC \\
\hline & M8b & CGTCACTAGCCGCCGACGggatccTTTC \\
\hline & $\mathrm{CE}_{\mathrm{as}}{ }^{\circ}$ & GCGCGCCGTCGGCGGCTAGTGACGTCACGG \\
\hline & $\mathrm{CEl}_{3}{ }^{*}$ & CCGTGACGTCACTAGC \\
\hline & $\mathrm{CE}_{\mathrm{as}}{ }^{-\infty}$ & GCTAGTGACGTCACGG \\
\hline & $\mathrm{M} 7 \mathrm{aL}^{\infty}$ & CACGGGCCGTGAggatccTAGCCG \\
\hline & M7bL ${ }^{*}$ & CACGGGCCGTGACGTCACggatcc \\
\hline & $\mathrm{CE}^{\mathrm{m}} \cdots$ & 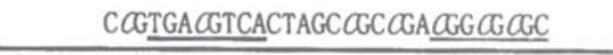 \\
\hline
\end{tabular}

*Double-stranded oligonucleotides. The ATF/CREB site is underlined with thick lines while E2F-DP/SP1 site underlined with thin lines.

**Single-stranded oligonucleotides in which the subscript “s" designates sense strand and "as" designates anti-sense strand.

***Double-stranded oligonucleotides with CpG specially methylated in vitro by SssI methylase. The italiccharacter designates the methylated $\mathrm{C}$ residue. 
where the TGACGTCA sequence (ATF/CREB consensus) was changed to TGAgGatc, i.e., 4/8 bp was altered. In mutant pM7b where the sequence TAGCCG being outside of the ATF/CREB site was changed to GGATCC, it exhibited a much higher promoter activity (40\% of the wild type) than that of pM7a. Both pieces of evidence suggested the vital importance of ATF/CREB site to the promoter function. The promoter activities were also reduced significantly in mutants pM8a and pM8b (23\% and $24 \%$ of the wild type, respectively), but only $\mathrm{pM} 8 \mathrm{~b}$ had the E2F-DP site replaced. In view of the lower similarity of this sequence with the consensus of the authentic E2F-DP site, the functional importance of this sequence, represented by the original sequence that was replaced by mutants pM8a and pM8b, respectively, may be mediated by the unknown protein factors other than the E2F-DP. This notion was substantiated by the observations that co-transfection with the mammalian expression E2F1 or DP1 constructs failed to affect the promoter activity of $\mathrm{pF}$ (see Fig 10A). As the mutant pM6a with the AP-2 site being replaced still had at least half of the wild type promoter's activity, this site may not be as important as aforementioned sites. In conclusion, the -40 to -12 segment, designated as CE fragment, where an ATF/CREB site resides, has a prominent role in the RNMTL1 promoter activity (Fig 5, 6).

ATF/CREB like protein factors can specifically bind to the CE fragment, which may have a functional implication to the RNMTL1 promoter activity in cells

To characterize the protein factors capable of binding the CE fragment, we carried out the electrophoresis mobility shift assay to look for the sequence specific binding proteins in the nuclear ex-

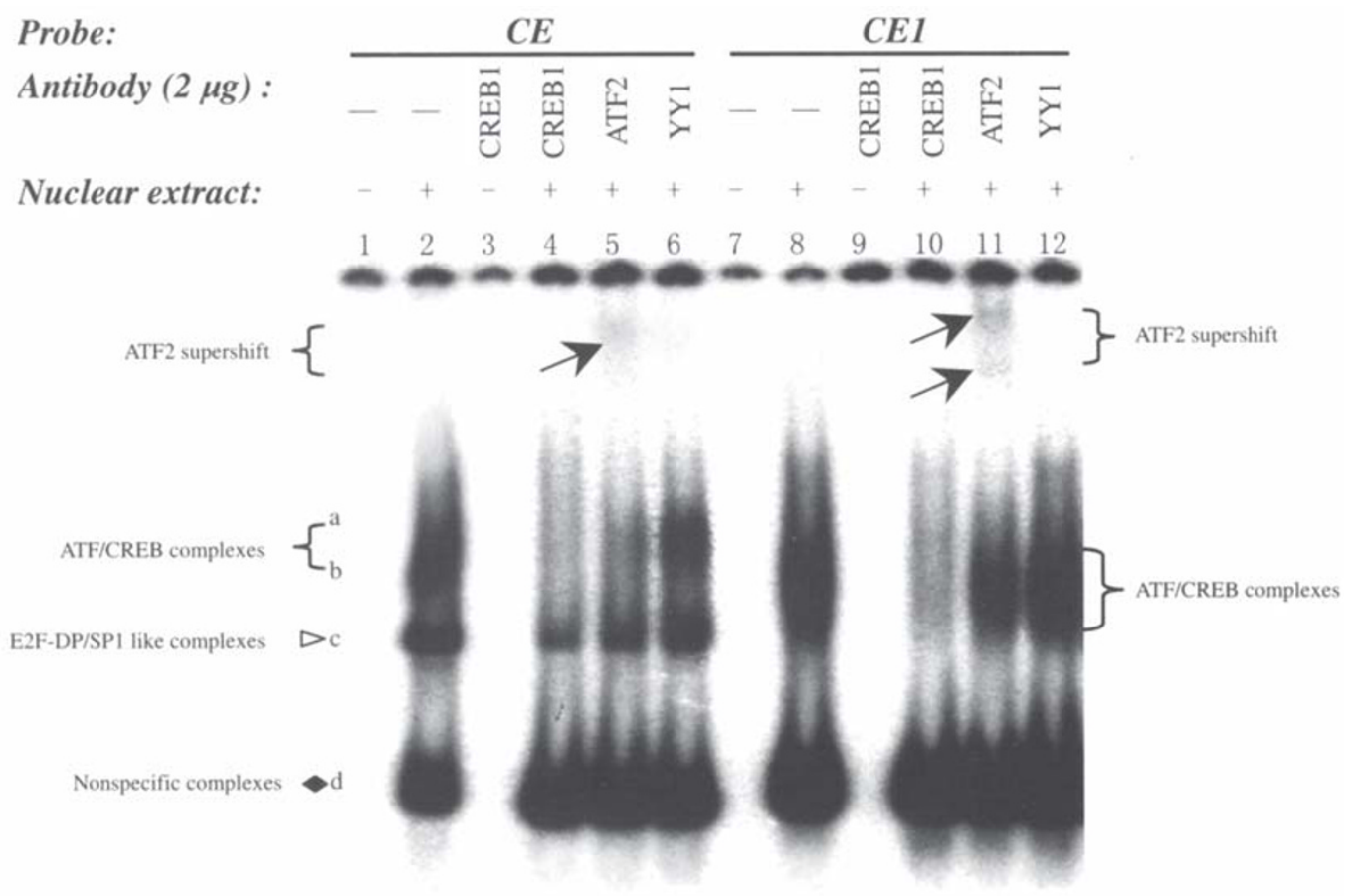

Fig 8. Identification of ATF/CREB family proteins bound to the ATF/CREB site within CE fragment. $5 \mu \mathrm{g}$ SMMC7721 nuclear extracts were incubated with ${ }^{32} \mathrm{P}$-labelled double-stranded oligonucleotides CE or CE1 in the presence of specific antibodies. Lane 2 and 8, no antibody control; lane 3 and 9, no nuclear extract control; lane 4 and 10, rabbit polyclonal antibody recognizes the bZIP domain of CREB1/ATF1/CREM1; lane 5 and 11, ATF2-specific antibody; lane 6 and 12, YY1-specific antibody. The positions of ATF2 supershift, ATF/CREB complexes is marked by arrows (a, b), E2F-DP/SP1 like complexes is marked by light arrowhead (c) and nonspecific complexes black diamond (d). 
tracts from SMMC7721 cell interacting with each of the three ${ }^{32} \mathrm{P}$-labelled double-stranded oligonuc leotide probes, respectively, i.e., CE (-40 to -12 , includes ATF/CREB site and E2F-DP/SP1 site), CE1 (-40 to -26, includes ATF/CREB site) and CE2 (-25 to -12, includes E2F-DP/SP1 site). There were four distinct shifted bands, representing the DNA/protein complexes concerning the $\mathrm{CE}$ fragment and the nuclear extract from SMMC7721 cells(numbered a $\rightarrow$ d; Fig 7A, lane 2). The complexes ( $\mathrm{a}, \mathrm{b}$, and $\mathrm{c}$ ) were com-
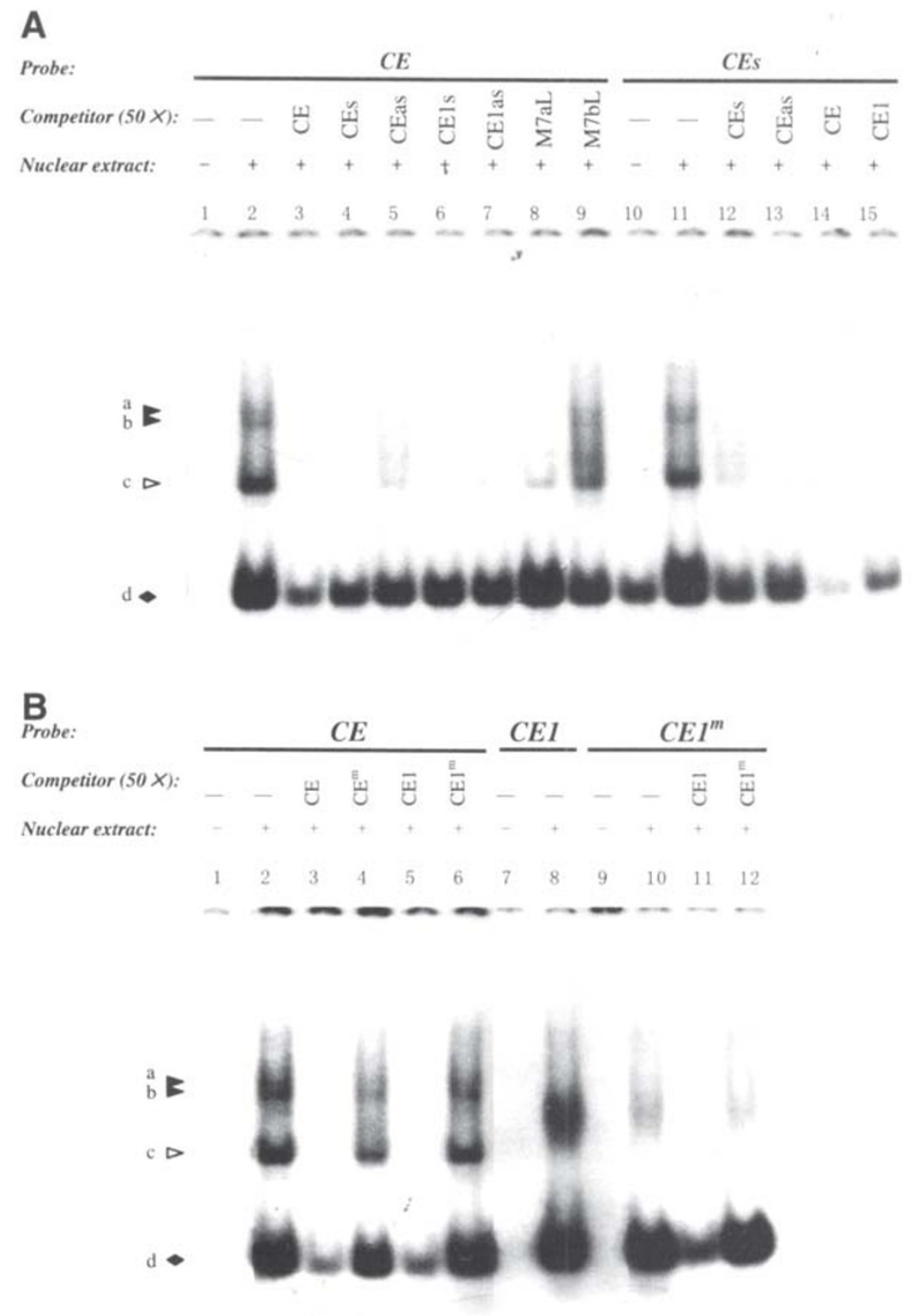

Fig 9. The ATF/CREB binding of the single strand or methylated oligonucleotides by EMSA A, identification of single strand binding activity of ATF/CREB site. $5 \mu \mathrm{g}$ SMMC7721 nuclear extracts were incubated with ${ }^{32} \mathrm{P}$-labelled double-stranded oligonucleotides CE (lane 1-9) or single-stranded oligonucleotides CEs (lane 10-15). The formation of DNA-protein complexes was competed with 50-fold molar excess of various cold double-stranded (lane 3 , 14 and 15) or single-stranded (lane 4-9, 12 and 13) oligonucleotides (for sequences, see Tab 2). B, The CpG sitespecific methylation within ATF/CREB site resulted in a reduction of binding activity. The formation of DNA-protein complexes were competed with 50-fold molar excess of $\mathrm{CpG}$ site-specifically methylated oligonucleoties $\mathrm{CE}^{m}$ (lane 4), $\mathrm{CE}^{m}$ (lane 6) and the unmethylated control CE (lane 3), CE1 (lane 5). We also compared the binding ability of doublestranded oligonucleotides $\mathrm{CE} 1$ with that of $\mathrm{CpG}$ methylated $\mathrm{CE} 1^{m}$ (lane 7-10) without or with 50-fold molar excess of competitor CE1 (lane 11) and CE1 $1^{m}$ (lane 12). 
pletely abolished by a 20 to 100 -fold molar excess of unlabelled CE oligonucleotide (Fig 7A, lanes 3-5). In the case of $\mathrm{CE} 1$, only three distinct complexes (numbered a, b, and d; Fig 7A, lane 7) could be detected. It is possible that complexes a and $b$ represented the complexes containing the nuclear factors bound to ATF/CREB site, while complex c represented the complexes containing the E2F-DP/SP1 site. As only complex d could be detected when CE2 was used as probe, (Fig 7A, lanes 12-15), formation of complexes $\mathrm{a}, \mathrm{b}$ and $\mathrm{c}$ may depend upon the integrity of ATF/CREB site. Complex d appeared in all cases and could not be completely abolished even by 100 -fold molar excess of cold probe. They, thus, might be the nonspecific complexes in nature.

To further delineate the nucleotide sequences essential to the specific DNA-protein interactions of CE fragment, a set of CE mutants were made, in which 6 to 12 nucleotides were mutated and assayed for their competition potency on the DNA-protein interactions concerning $\mathrm{CE}$ fragment (the sequences of different mutated oligonucleotides are listed in Tab 2). By using 50-fold molar excess of CE mutants, the relative importance of the individual nucleotides to the sequence-specific binding could be estimated by EMSA. As shown in Fig 7B, ATF/CREB site-specific complexes a and $b$ could be effectively eliminated by 50 -fold of wild-type CE or CE1 oligonucleotide and 50-fold molar excess of mutants, in which the mutations occurred outside of the ATF/CREB site (lanes 3, 4, 7,11-13). On the contrary, complexes $\mathrm{a}$ and $\mathrm{b}$ could not be completely abolished when mutations occurred within the ATF/CREB site (lanes $5,6,8-10,14)$. The profile of E2F-DP/SP1 site-specific complex c seemed complicated. Mutants with an intact E2F-DP/SP1 site maintained the full competency to destroy the binding of E2F-DP/SP1 site by the nuclear proteins in SMMC7721 cells (lanes 5, 9-11). However, the oligonucleotides with E2F$\mathrm{DP} / \mathrm{SP} 1$ site mutated or deleted but ATF/CREB site intact still retained this competition potency (lanes 7,12 ). Only the oligonucleotides with both sites being mutated failed to eliminate this binding (lanes $6,8,14)$. These results indicated that the formation of ATF/CREB site-specific complexes requires an intact ATF/CREB site while the formation of E2F-
DP/SP1 site-specific complex requires both E2F$\mathrm{DP} / \mathrm{SP} 1$ site and its adjacent ATF/CREB site intact.

Confirmation of the direct interaction between the $A T F / C R E B$ proteins and their cognate sequence within the CE fragment with specific antibodies

To identify which members of ATF/CREB family are responsible for RNMTL1 promoter activation, we performed supershift experiments in which 32Plabelled CE or CE1 probe was incubated with nuclear extract in the presence of specific antibodies to ATF2, CREB1 and YY1 proteins, respectively. As shown in Fig 8, lanes 4 and 10, addition of the antibody against the bZIP DNA-binding domain of CREB1 in the binding reaction abolished the complexes a and $b$, manifesting the presence of the CREB1 protein in these two complexes. While addition of ATF2 antibody, the antigen of which is outside of the DNA binding domain, resulted in a supershifted band (Fig 8 , lanes 5 and 11). As a negative control, addition of the YY1 antibody did not affect either the formation or the mobility of any of these CE-specific complexes. These observations strengthened the conclusion that the ATF/CREB site within CE fragment indeed interacts with multiple ATF/CREB family proteins including ATF2 and CREB1 in cells and is responsible for the promoter activity of the RNMTL1 gene.

The ATF/CREB proteins can sequence-specifically bind to the single-stranded ATF/CREB oligonucleotide

As the consensus of ATF/CREB: "TGACGTCA" is a perfect inverted repeat, it tends to form a cruciform secondary structure in solution[16]. It is likely that the sequence-specific binding of the ATF/CREB protein is mainly mediated via binding to the cruciform structure rather than the primary sequence. Thus, this protein should have a compatible binding capacity to the single-stranded oligonucleotides, which can also form the loop structure and equivalent to one of the two loops in the cruciform structure by its double-stranded counterparts. To test this working hypothesis, we performed EMSA using ${ }^{32} \mathrm{P}$ labelled single-stranded oligonucleotide CEs with nuclear extract prepared from SMMC7721 cells. Four distinct CE-specific complexes could also be detected and abolished by 50 -fold molar excess of competitor 
$\mathrm{CE}_{\mathrm{s}}, \mathrm{CE}_{\mathrm{as}}, \mathrm{CE}$ and $\mathrm{CE} 1$ (Fig 9A, lanes 12-15). Moreover, the single-stranded oligonucleotide $\mathrm{CE}_{\mathrm{s}}$, $\mathrm{CE}_{\mathrm{as}}, \mathrm{CE} 1_{\mathrm{s}}$ and $\mathrm{CE} 1_{\text {as }}$ could compete as effectively as the double-stranded oligonucleotide CE (Fig 9A, lanes 3-7). With the ATF/CREB site mutated, the single-stranded oligonucleotide $\mathrm{m} 7 \mathrm{aL}$ failed to compete (lane 8). On the contrary, when the mutation occurs outside of ATF/CREB site, the singlestranded competitor $\mathrm{m} 7 \mathrm{bL}$ maintained the competition ability (lane 9). So far, our working hypothesis has been proved to be correct.

The ATF/CREB site: "TGACGTCA" contains a central CpG dinucleotide, and methylation of this site may result in loss of specific factor binding as well as loss of transcriptional activity both in vitro and in vivo[17]. We compared the $\mathrm{CE}$ with $\mathrm{CE} 1, \mathrm{CEm}$ and $\mathrm{CE} 1^{m}$ oligonucleotides for their capacity of competing the binding of nuclear factors to the $\mathrm{CE}$ oligonucleotides by means of EMSA, in which both $\mathrm{CE}^{m}$ and CE $1^{m}$ oligonucleotides were methylated by SssI methylase beforehand. As shown in Fig 9B, the CEspecific protein complexes were more prominent in the presence of $\mathrm{CE}^{m}$ and $\mathrm{CE}^{m}$ than the corresponding unmethylated oligonucleotides respectively.
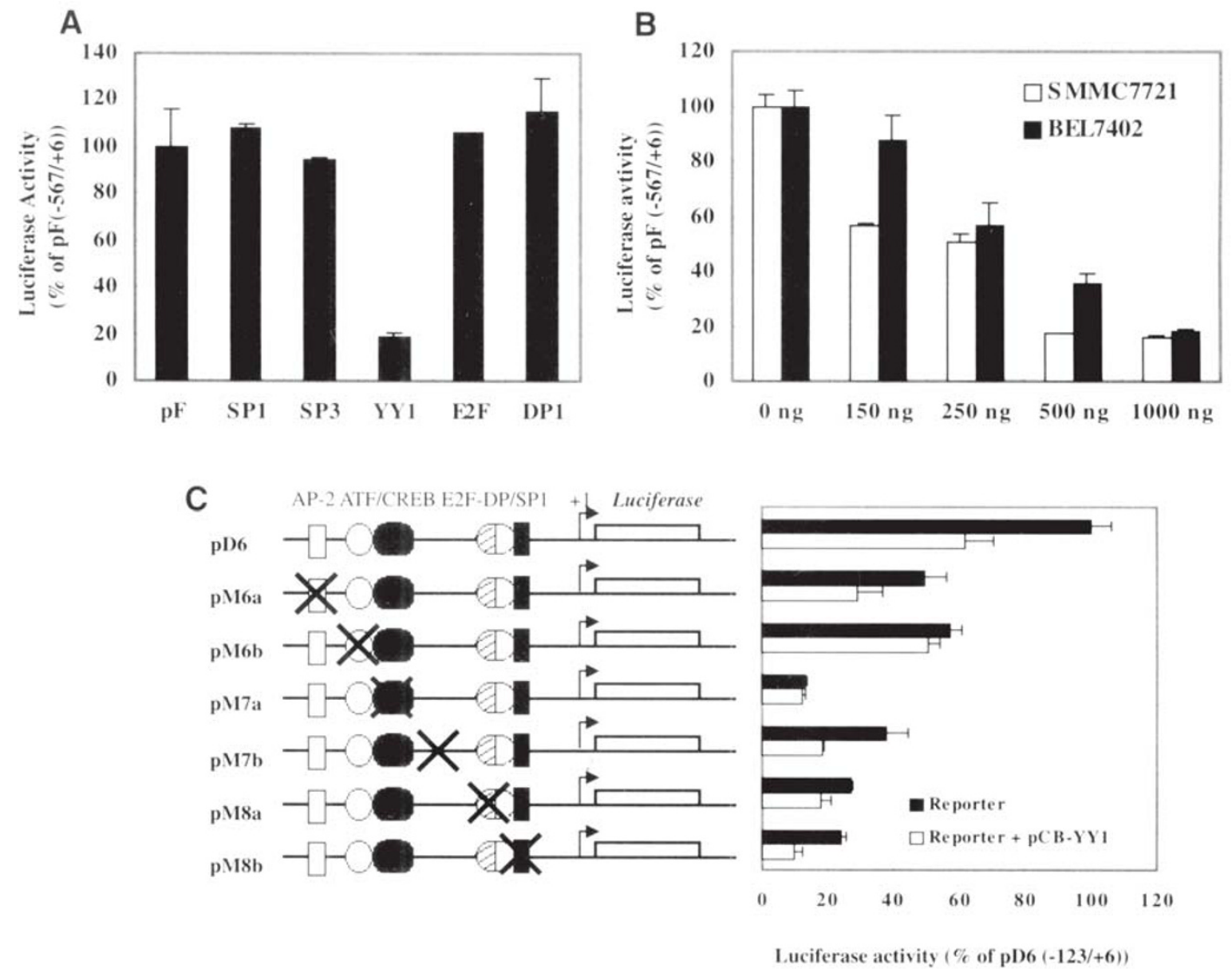

Fig 10. YY1 represses the promoter activity of the $R$ NMTL1 gene A, Co-transfection of the SP1, SP3, YY1, E2F1 and DP1 expression constructs $(1 \mathrm{mg})$, respectively, with pF(-567/+6) in SMMC7721 cells. B, Effect of co-transfection of YY1 expression vector pCB-YY1 on the RNMTL1 promoter activity in SMMC7721 and BEL7402 cell lines. $1 \mu \mathrm{g}$ of $\mathrm{pF}(-567 /+6)$ promoter-reporter construct plus up to $1 \mu \mathrm{g}$ of pCB-YY1 were co-transfected with a control plasmid (pRL-TK) and assayed $24 \mathrm{~h}$ post-transfection. C, YY1-mediated transcription repression of RNMTL1 promoter requires an intact ATF/CREB site. A set of sequence replacement mutated promoterreporter constructs (pM6a to pM8b, for sequences see Fig 6) plus a wild-type control (pD6) were transfected into SMMC7721 cells with or without YY1 expression vector pCB-YY1 respectively. 
$Y Y 1$ 's repression of the promoter activity of the RNMTL1 gene is mediated via the ATF/CREB site

An alternative approach to confirm the involvement of a transcription factor in the transcription of a given promoter is to assess the effect of the exogenously introduced transcription factor by the transient transfection/reporter assay, the cognate site(s) of which is (are) within the tested promoter to drive the luciferase reporter gene. As shown in Fig 3, there are a variety of the cis-elements within the promoter $(-567$ to +6$)$ of the RNMTL1 gene, noticeably, three SP1 sites ( -467 to -458 , -222 to -214 , and -100 to 94 ), and three E2F-DP/SP1 sites (-425 to -420 , 244 to -238 and -18 to -12 ). To evaluate whether these sites are functionally important in cells, we transfected into the SMMC7721 and BEL7402 cells, respectively, with the mammalian expression constructs of the human SP1, SP3, E2F1, DP1 and YY1 along with $\mathrm{pF}(-567$ to +6$)$. YY1 was chosen as an unrelated control, since its cognate site is absent in this region. As shown in Fig 10A, in the experiments using $1 \mathrm{~m}$ g each of the mammalian expression constructs encoding SP1, SP3, E2F1, DP1 and YY1, respectively with $1 \mathrm{mg} \mathrm{pF}$, only YY1 reduces the reporter expression down to $20 \%$ of the mock control's level in the transfected cells, while all the rest have no detectable effects. The inertness of the transcription factors, SP1, SP3, DP1 and E2F1 in this test has following plausible explanations: 1 , the consensus of those sites were less significant, i.e., the expected value is below $10-1 ; 2$, these sites are not accessible due to the particular chromatin structure, the similar structure can be fairly precisely transferred to the inputted reporter construct, $\mathrm{pF}$; 3 , the endogenous level of the expression of the factors were already at the functionally saturated level, additional amounts of exogenously supplied factors would not result in any significant effect.

Increased expression of YY1 in the transfected cells by more constructs leads to a dose-dependent repression as shown in Fig 10B. As there was no motif recognized by YY1 within the minimal promoter, YY1 mediated repression of the RNMTL1 gene transcription should act via other sequence specific DNA-protein interaction, the protein-protein interaction in which the YY1 presides. To verify this hypothesis, we tested the YY1's repressing effect on a set of the sequence-replaced mutants. As shown in Fig 10C, only pM6b and pM7a, in which the ATF/CREB sites were mutated, resisted this repression. Therefore, the received end in the minimal promoter for the YY1' s repression of transcription is the cis-element bound by the ATF/CREB proteins.

In this connection, we used a semi-quantitative PCR to estimate the relevant level of expression of both YY1 and CREB1, respectively. As shown in Fig 11, the expression level of the CREB1 was relatively lower in both cell lines and normal liver (lanes 1-4) than in patient samples (lanes 5-8). However, the level of the YY1 expression is either higher in cell lines (lanes 1-3) or lower in the normal liver and non-cancerous tissues (lanes 4, 5, and 7) than the HCC tissues of the same patients (lanes 6 and 8). The significance of this expression pattern remains to be evaluated.

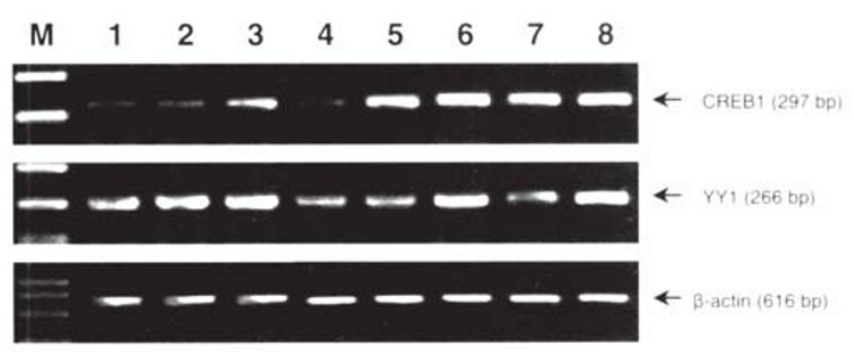

Fig 11. Expression profile of the CREB1 and YY1 genes in cell lines and tissue samples RT-PCR was performed using total RNA from LO2, SMMC7721, BEL7402 (lane 1-3), tissue samples from normal human liver (lane 4), HCC tissues D15C (lane 6), G62C (lane 8) and adjacent noncancerous liver tissues D15N (lane 5), G62N (lane 7).

\section{DISCUSSION}

The annotation of this newly discovered 17p13.3 gene according to its sequence similarity to the known proteins from other organisms

The rapidly accumulated sequence information from various organisms in the public database has drastically facilitated the process of establishing the evolutional relationship of a given newly discovered gene. The RNMTL1 (Accession No. AF177344) gene was one of thirteen genes cloned from the $116 \mathrm{~Kb}$ fragment within the $17 \mathrm{p} 13.3$ (6 MB) region that 
displays a highest frequent loss of heterozygosity in the human hepatocarcinoma. To understand its gene function, we blasted the protein sequence database with the RNMTL1 amino acid sequence and identified a high conserved region with methylases from various microorganisms, within the RNMTL1 gene [18],[19]. As shown in Fig 12, the multiple alignment of this region with the SpoU rRNA and TrmH methylase [Escherichia coli], as well as PET56 [ Saccharomyces cerevisiae] illustrates the homology in the region, function of which is to transfer methyl group to rRNA molecule[19],[20]. The percentage of identity is between $32 \%$ to $42 \%$ at level of amino acid sequence. Therefore we annotated this newly discovered gene as RNMTL1: standing for RNA methylatransferase like 1 gene. However, whether the RNMTL1 gene indeed encodes a RNA methyltransferase protein remains to be experimentally determined.

Transcription regulation of the RNMTL1 gene and the molecular approaches that we adopted

Although the expression profile of the RNMTL1 gene does not show any hepatoma specificity at the level of mRNA (Fig 1), indicating that it may not fall into the category of the conventional tumor suppres- sor genes or its relevant function and expression may be at the levels other than transcription, the study of its transcription regulation remains of importance as the RNMTL1 gene is a newly discovered gene, the expression control of which may possess a unique feature that others lack. Therefore, we conducted a set of molecular structural and functional investigation of the primary structure of the RNMTL1 gene promoter. By primer extension analyses, we identified four starts that could be divided into two groups, each containing two sites one following another. There are only 18 nucleotides apart between these two groups (Fig 2). As the deletion mutants pD10(201/-3), in which both downstream sites (+1 and 1 ) were deleted, led no more than $40 \%$ reduction of promoter activity, despite that pD11(-201/-18) where the upstream starts (-19 and -20) were retained had no promoter activity (Fig 4), all the four sites were required for the full function of this promoter. In this connection, the mutant pM8a in which one of the two upstream starts (-19C and $-20 \mathrm{~A})$ were replaced with BamHI site (as a result, $\mathrm{AC}>\mathrm{TC}$ ), the promoter activity dropped to $20 \%$ of the wild-type level (Fig 6), indicating the functional importance of the upstream start of transcription for the promoter activity of the RNMTL1 gene.

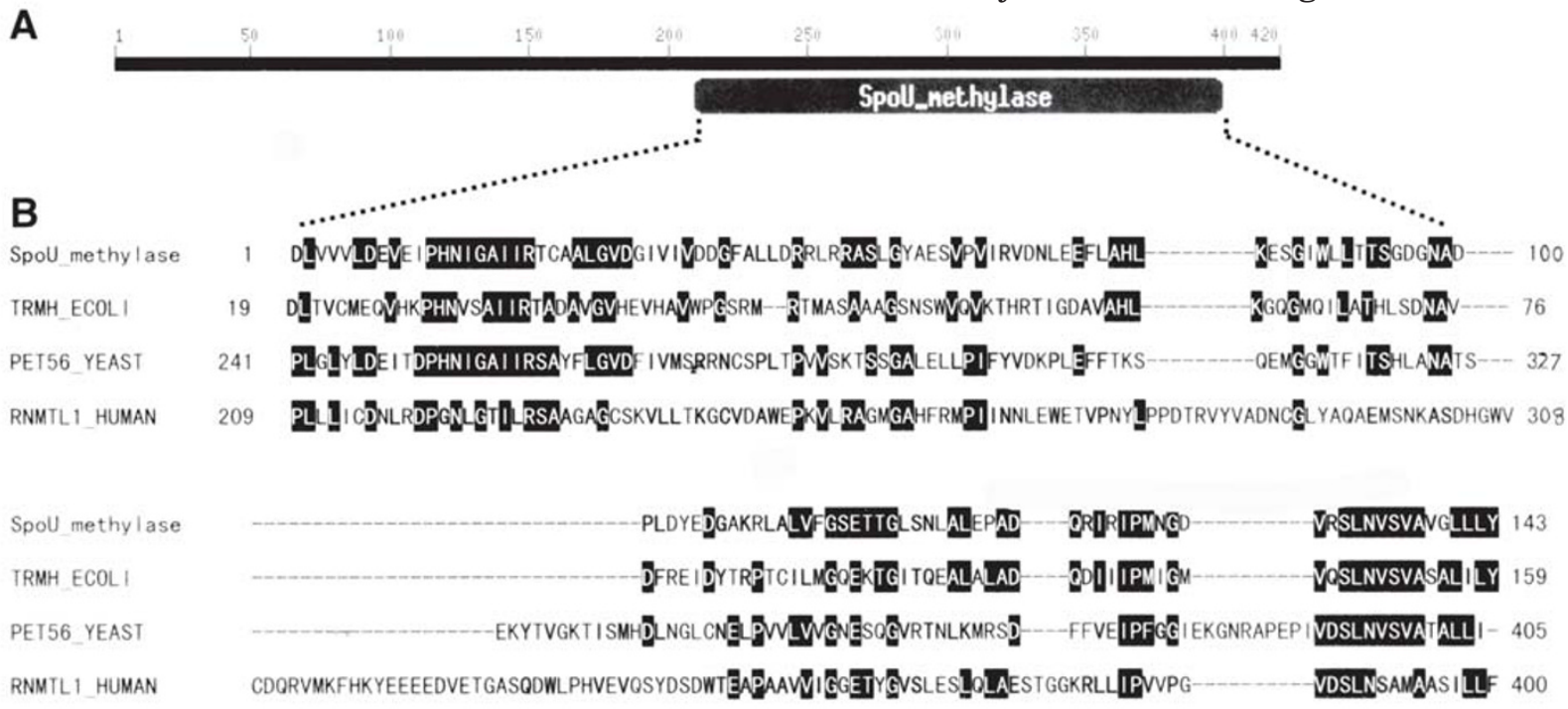

Fig 12. Homology analysis by a multiple alignment of the RNMTL1 protein with E. Coli SpoU methylase, TrmH family protein, S. Cerevisiae protein PET56 A, Human RNMTL1 protein contains a conserved domain belongs to SpoU-methylase family revealed by searching the conserved domain database (NCBI). B, Multiple alignment of RNMTL1 protein with three other protein containing a SpoU-methylase domain. SpoU-methylase, E. Coli SpoU rRNA methylase; TRMH-ECOLI, E. Coli TrmH family protein; PET56 - YEAST, S. Cerevisiae protein PET56; RNMTL1-HUMAN, human RNMTL1 protein. The amino acid sequence of RNMTL1 was compared with that of three other proteins using CLUSTAL W software (http://www.ebi.ac.uk/ clustalw/). The black boxes indicate the identical amino acids, and the gray boxes indicate the positive amino acids in these proteins. 
After defining the 5' and 3' boundaries of the minimal promoter of the RNMTL1 gene by analyzing a spectrum of the exo-deletion mutants of the promoter, we discarded the conventional approach, i.e., focusing at the consensus sequences recognized by the known transcription factors, the database of which is compiled chiefly based upon the information from the in vitro characterization of the sequence-specific DNA-protein bindings[21]. Instead, we performed the functional analysis of a range of the mutants, in which 6 or 12 nucleotide sequences were systematically altered. The rationales of our efforts are 1, the significance of the consensuses in such prediction softwares, including the one that we used, often suffer from the lack of the in vivo functional substance; and 2, the likelihood to overlook the novel cis-elements absent in the database and over-interpret the importance of the existing ones is very high. As shown in Fig 5 , the sequence-replaced mutants, i.e., pM1, 2, 3, 4, and 5, displayed the promoter activity at a compatible level of reduction from the wild-type's. Among them, only pM1 might destroy the SP1 site, the only site detected by computer prediction, and the rest mutants did not affect any consensus recognizable by the same software. Obviously, the studies using the classical approach, namely, focusing at the consensus sequence recognized by the known transcription factor, would misinterpret the significance of the SP1 site, most likely to be biased towards the overstating.

Although the transient transfection/report assay is a powerful approach widely used in the study of the kind described in the report, it is necessary to confirm the experimentally derived conclusion with other approaches including biochemical characterization of the relevant intermolecular interactions. Therefore, after fishing out the crucial segments CE (-40 to -12) (Fig 5 and 6), we carried out detailed characterization by the electrophoresis mobility shift assay of the sequence-specific interaction between the $\mathrm{CE}$ fragment and the nuclear proteins from the cell lines that were used as recipients for transfection analysis. As shown in Figs 7-9, the identity of the crucial element largely responsible for the transcription vigorousness of the RNMTL1 gene promoter, i.e., ATF/CREB site and their cognate transcription factors was confirmed by the following: 1 , the candidate site within the RNMTL1 gene pro- moter is $100 \%$ identical to the consensus[16]; 2 , the interaction with relevant fragments in absence or presence of the non-specific and specific competitors did unambiguously support the conclusion drawn from the transfection experiments; 3 , using specific antibodies against the ATF and CREB in the supershift assay produced supportive data (Fig 8). However, whether other members of the ATF/ CREB family participate in both the promoter activity and formation of the DNA-protein complexes remains to be determined.

The DNA-protein interaction of the ATF/CREB is controlled at the levels above the primary structure

The ATF/CREB family of trans-activators have the following modular domains: 1 , a centrally located 60-amino-acid kinase-inducible domain (KID); 2 , the hydrophobic glutamine-rich trans-activating domains, designated $\mathrm{Q} 1$ and $\mathrm{Q} 2$, at the $\mathrm{N}$-terminal end; 3, a basic region/leucine zipper (bZIP) domain responsible for the sequence-specific binding and the homo- or hetero-dimerization that was at the carboxyl-terminus[22], [23]. Differential regulation of target genes by cAMP, through CREB, is achieved by varying the sequence composition and placement of the ATF/CREB site on the promoter[24], [25]. In addition, the post-translational phosphorylation mediated by the hormone-induced accumulation of cAMP activates protein kinase A (PKA), which phosphorylates CREB at serine 133 and further enhances transcription activation[26]. The cross-talk of the bound members of this transactivator family with the general transcription factors that are mainly responsible for accurate initiation of in vitro transcription, such as TFIIA, TFIIB, etc., is thought to be essential to the transcription activation of the promoter of this kind[24]. In this context, there were the reports for that ATF/CREB family members qualitatively alter the binding of TFIID and associated proteins to a target promoter, facilitating subsequent interaction with TFIIB and other general transcription factors and increasing protection downstream of the TATA element[27],[28].

The cis-element recognized by the member of the ATF/CREB family is cyclic AMP response element that consists of the palindromic octanucleotide "TGACGTCA"[16],[25]. In view of the natural tendency for the palindromic sequence to form the cru- 
ciform structure in the form of the double-stranded entity, and a half of the cruciform in the singlestranded entity, we carried out the EMSA with the single-stranded CE sequence, attempting to assess the importance of the secondary structure in the sequence specific interaction between the ATF/CREB protein and its cognate element. In theory, the single-stranded probes formed from either strand should be the same at the level of the secondary structure (Fig 13, A and B). As shown in panel A, Fig 9, there was no difference between the interactions of ATF/CREB type proteins in the nuclear extracts with single-stranded or double-stranded probes. The unit of the repeat is only four nucleotide in length, the tendency for the double-stranded form of this sequence to form the cruciform should be less potent than that for its single-stranded counterparts to form the a structure, equivalent to the half of the cruciform. For the same reason, the equilibrium between the cruciform structure and the classic double-stranded DNA is toward the latter form (Fig 13A). Our observation (Fig 9) showing that the single-stranded form is equally competent to its double-stranded entity, may suggest the cruciform structure is likely to be the dominant secondary structural form of DNA in the DNA-protein complexes. However, the issue concerning the structural nature of the DNA for the initial binding remains to be a matter of speculation. It is quite likely that the cruciform structure formed by the double-stranded ATF/CREB site containing oligonucleotides is a must for its cognate factor to bind, and such a binding subsequently stabilizes the complex in which the cruciform is preferred to the classic form of double-stranded structure. However,

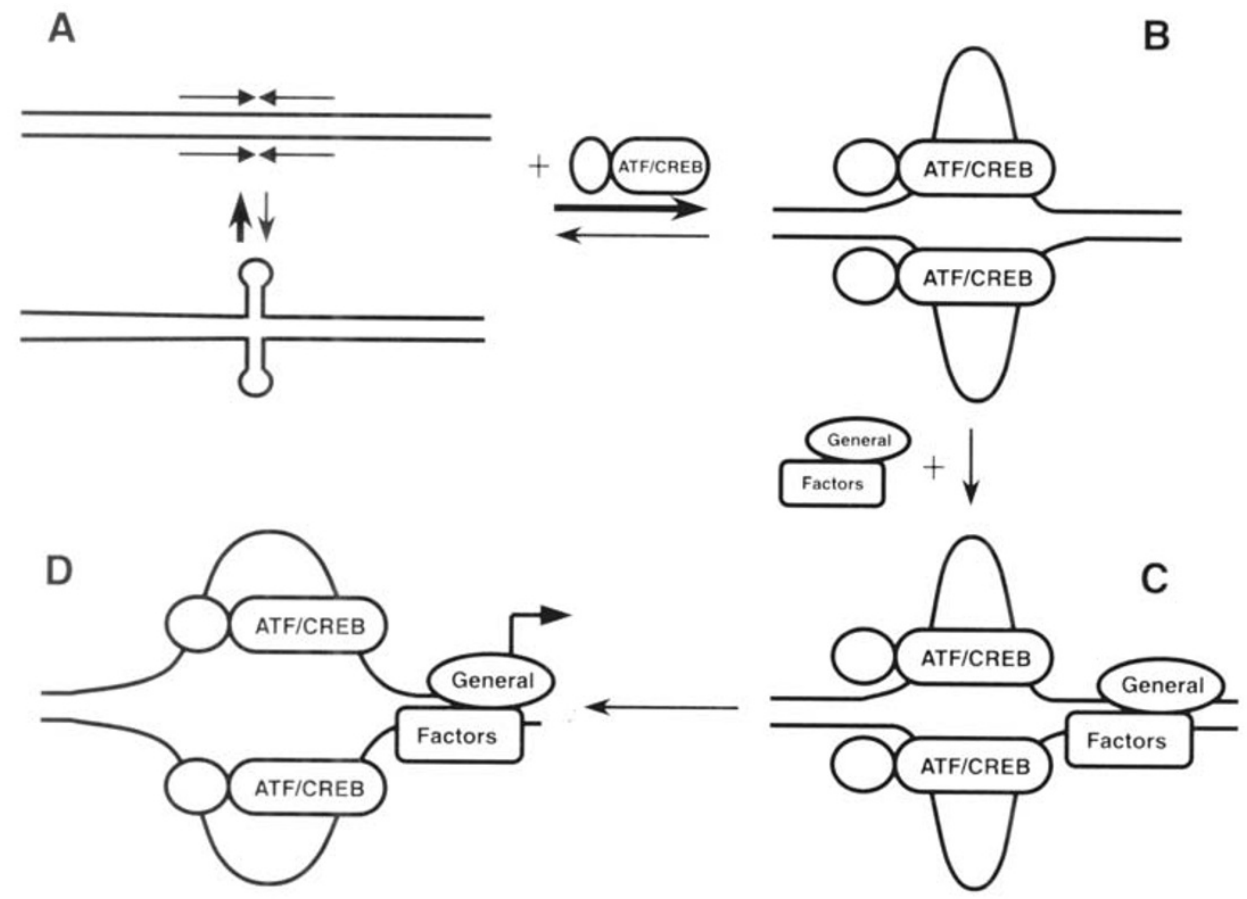

Fig 13. A model for the structural specific binding by the ATF/CREB factors to the cruciform of its cognate palindrometype sequence in solution, to interpret the compatible levels of their binding to both double- and single-stranded oligonucleotides and their functional implication in gene transcription. A, The equilibrium between the classic form and cruciform of the double-stranded DNA favors to the former form, indicated by the thicker arrow; B, When ATF/ CREB proteins are present, they either preferentially bind to and stabilize the cruciform or bind to the classic form and convert it to the cruciform; $\quad \mathbf{C}$, This interaction results in both initial melting of the DNA region covered by ATF/CREB and extending of the melt region in both directions; $\mathbf{D}$, The melting region continues extending in response to the needs of the full-blown transcription. 
a different scenario is also quite possible that the ATF/CREB proteins can bind to its cognate sites in the form of the classic double-stranded DNA structure with an adequate but low affinity, and the initial binding subsequently induce and promote the formation of the cruciform of the DNA (Fig 13B). In view of the high dynamic nature and plausibility of DNA secondary structures in solution, the ATF/ CREB site based protein-DNA interaction may be the very early event of a chain reaction leading to a full-blown transcription (Fig 13C and D).

DNA methylation has been widely claimed as a powerful alternative to the various molecular genetic mechanisms for cells to alter the expression of a given gene in response to biological or pathological stimuli [15]. It has been accounted for the loss of function of a large number of the tumor suppressor genes in human tumors[29]. In higher organisms, the overwhelming majority of, if not all, methylation is to add methyl group at the C5 in the cytosine in the form of $\mathrm{CpG}$ dinucleotide. Methylation of the cytosine base would change the high-order structure of DNA, in turn affecting the affinity of the motifs to their cognate protein partners. There is a $\mathrm{CpG}$ within the ATF/CREB octamer site (5' TGACGTCA $3^{\prime}$ ), so that we had tested whether methylation of this $\mathrm{C}$ residue of the $\mathrm{CpG}$ sequence would affect the sequence-specific binding. As shown in panel B, Fig 9 , methylation had a devastating effect on this sequence-specific interaction. However, how signifi- cant this observation is meant tothe promoter activity of the RNMTL1 gene remains to be investigated. In view of the wide presence of the ATF/CREB sites within the promoter $\mathrm{CpG}$ islands, which is present in over $50 \%$ of the protein coding genes, the methylation mediated gene silencing mechanisms acting by destroying the ATF/CREB protein' $\mathrm{s}$ binding to its cognate site is a good alternative to inactivate the transcription of the genes in either normal and pathological situations (including the tumors).

YY1 acts as negative regulator for the RNMTL1 gene transcription via an interfering mechanisms aiming at the ATF/CREB proteins' interaction with their cognate sites

YY1, a well known versatile transcription factor, binds to a specific DNA sequence (CGCCATNTT) that is located in many different promoters and functions as an activator, a repressor or an initiator of transcription[30], [31]. In this study, we observed for the first time that YY1 represses the promoter activity of the RNMTL1 gene via a novel mechanism in which YY1's binding to its cognate sites was not involved. There were evidences for YY1' $\mathrm{s}$ action to be mediated by its interaction with ATF/CREB trans-activator (Fig 14A)[32]. The ATF/CREB-YY1 interaction has been demonstrated in c-fos protooncogene promoter[33], [34]. Furthermore, thedirect interaction between YY1 and ATF/CREB has also been biochemically proved[34],[35]. However, in

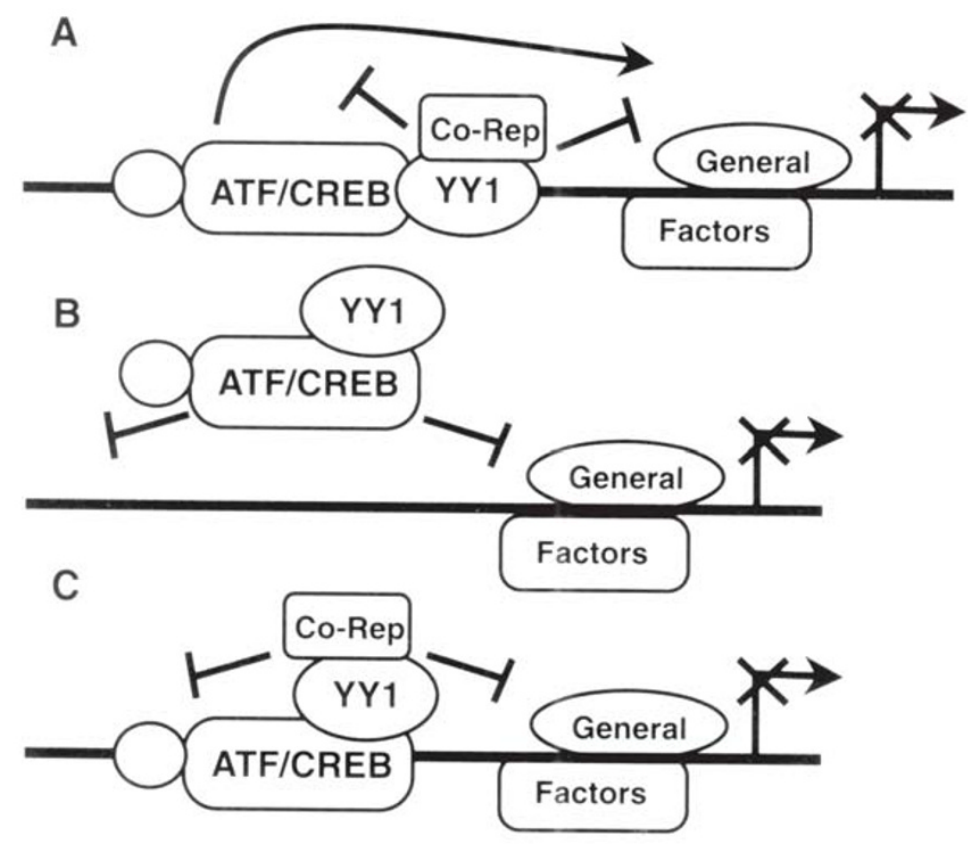

Fig 14. Models of the YY1-mediated repression A, YY1 interacts directly with ATF/CREB in c-fos promoter, in which YY1 bound to its consensus DNA sequence (-54 to -47$)$ adjacent to the ATF/CREB site $(-67$ to -60$)$. Such an interaction results in recruitment of transcription repressor or the interference the formation of the transcription active complexes with the basic transcription machineries. B/C, YY1 represses transcription of RNMTL1 promoter by protein-protein interaction between YY1 and ATF/CREB complexes, in absence of the YY1' $\mathrm{s}$ binding to its cognate site. YY1 prevents transcriptional activation of RNMTL1 promoter either by dismantling the transactivating ATF/CREB complexes (panel B), or recruiting the otherwise absent co-repressors (panel C). 
the case of c-fos, the DNA motif of YY1 is within the proximity of the ATF/CREB site, the protein interaction between YY1 and ATF/CREB would co-exist with each's sequence specific DNA-protein binding [33]. However, in the case of the RNMTL1 gene, YY1's repression of transcription did not need the YY1's binding to the promoter DNA (Fig 10). The direct interaction between YY1 and ATF/CREB would have to occur; otherwise, the ATF/CREB site dependence of the YY1 repression would be hard to be explained. Here we proposed a model to accommodate all the information, both in literature and in this report (Fig 14). Panel A, illustrates the suggested action by YY1 and ATF/CREB occurring at the c-fos promoter. In this case, the ATF/CREB site (-67 to $60)$ is only $5 \mathrm{bp}$ upstream of the YY1 site (-54 to 47), therefore, the DNA bounded forms of the ATF/ CREB and YY1 proteins are next to each other and have a direct physical interaction. Such an interaction would result in recruitment of other protein factors including chromatin remodeling elements and co-repressors to cause the otherwise actively occurring transcription to stop[33]. However, in the case of the RNMTL1 gene, the YY1 motif is absent within the promoter. Our data in Fig 10, clearly demonstrated that YY1 could repress the promoter activity of the RNMTL1 gene via its direct interaction with ATF/CREB proteins in absence of the YY1's DNA-protein interaction. It is likely that YY1 attaches to the bounded ATF/CREB complexes, resulting in dismantlement of the trans-activating complexes (panel B), or recruitment of the otherwise absent co-repressors (panel $\mathrm{C}$ ). The end results from either suggested pathways would be the same: the promoter activity was repressed as illustrated in Fig 10. However, as the protein-protein interaction is able to bring together the DNA regions, the linear distance between which can be many dozens of $\mathrm{Kb}$ [30], the possibility can be not completedly excluded that transcription regulation of the endogenous the RNMTL1 gene mediated by YY1 may be similar to the c-fos, except for that the YY1 site is located at a long distance away from the ATF/CREB site. In this connection, failure to detect any effects of the antiYY1 antibodies on the protein complexes where the ATF/CREB proteins take the center of stage (Fig 8), may suggest that in the un-transfected cells, the complexes of ATF/CREB with their cognate DNA sequence devoid of YY1 may be the predominant species to its least. This agreed well with a dosagedependent manner of the YY1 mediated repression (Fig 10B).

The results described in this report have laid a solid basis for us to further address the important questions as such the fine details of the molecular genetic mechanism underscoring the transcription regulation of the RNMTL1 gene including the aspects of the secondary structure of DNA, proteinprotein interaction as well as the chromatin structural contribution.

\section{ACKNOWLEDGMENTS}

This work is supported by the 973 projects of China (G1998051004) to Jingde Zhu and (G1998051200) to Dafang Wan, respectively. Thanks are due to Hongyu Zhang and other members in Jingde Zhu's lab for assistance and helps on numerous occasions.

\section{REFERENMCES}

[1] Fujimoto Y, Hampton L, Wirth PJ et al. Alterations of tumor suppressor genes and allelic losses in human hepatocellular carcinomas in China. Cancer Res 1994; 54:2815 .

[2] Nagai H, Pineau P, Tiollais P, Buendia MA, Dejean A. Comprehensive allelotyping of human hepatocellular carcinoma. Oncogene 1997; 14:2927-33.

[3] Fujimori M, Tokinom T, Harada H et al. Allelotype study of primary hepatocellular carcinoma. Cancer Res 1991; 51:89-93.

[4] Stack M, Jones D, Santibanez-Koref M et al. Detail mapping and loss of heterozygosity analysis suggests a suppressor locus involved in sporadic breast cancer within a distal region of chromosome band 17p13.3. Hum Mol Genet 1995; 4:2047-55.

[5] Piao Z, Park C, Park JH, Kim H. Allelotype analysis of hepatocellular carcinoma. Int J Cancer 1998; 75:29-33.

[6] Li D, Cao Y, Gu JR et al. Aberrations of p53 gene in human hepatocellular carcinoma from China. Carcinogenesis $1993 ; \mathbf{1 4}: 169-73$.

[7] Qin WX, Wan DF, Gu JR et al. Cloning and characterization of a novel gene (C17orf25) from the deletion region on chromosome $17 \mathrm{p} 13.3$ in hepatocellular carcinoma. Cell Res 2001; 11(3):209-16.

[8] Wang G, Huang CH, Gu JR et al. Genetic aberration in primary hepatocellular carcinoma: correlation between p53 gene mutation and loss-of-heterozygosity on chromosome 16q21-q23 and 9p21-p23. Cell Res 2000; 10: 311-23.

[9] Zhao XT, Wan DF, Gu JR et al. A Novel Growth Suppressor 
Gene on Chromosome 17p13.3 with a High Frequency of Mutation in Human Hepatocellular Carcinoma. Cancer Res 2001; 61:7383-87.

[10] Smale ST. Transcription initiations from TATA-less promoters within eukaryotic protein-coding genes. Biochimica et Biophucica Acta 1997; 1351:73-88.

[11]Zhu JD. Myeloid cell-lineage and premyelocytic-stagespecific-expression of the mouse myeloperoxidase gene is controlled at initiation as well as elongation levels of transcription. Cell Res 1999; 9:107-34.

[12] Zhu JD. FT I, a novel positive myeloid-lineage-specific transcription regulatory element within the mouse myeloperoxidase gene enhancer, En 1. Cell Res 1995; 5: 75-91.

[13] Zhu JD. The myeloid-lineage-specific enhancer of the mouse myeloperoxidase gene consists of three cis-elements defined as in vitro DNase I footprints. FEBS Letters 1994; 339:243-48.

[14] Wingender E, Chen X, Schacherer F et al. TRANSFAC: an integrated system for gene expression regulation. Nucleic Acids Res 2000; 28(1):316-9.

[15] Jones PA, Baylin SB. The Fundamental Role of Epigenetic Events in Cancer. Nature Reviews 2002; 3:41528.

[16] Craig JS et al. Consensus and variant cAMP-regulated enhancers have distinct CREB binding properties. J Biol Chem 2000; 27:11719-28.

[17] Iguchi-Ariga SM, Schaffner W. CpG methylation of the cAMP-reponsive enhancer/promoter sequence TGACGTCA abolishes specific factor binding as well as transcriptional activation. Genes and Development 1989; 3:612-9.

[18] Persson BC, Jager G, Gustafsson C. The spoU gene of Escherichia coli, the fouth gene of the spoT operon, is essential for tRNA (Gm18) 2'-O-methyltransferase activity. Nucleic Acids Res 1997; 25(20):4093-7.

[19] Koonin EV, Rudd KE. SpoU protein of Excherichia coli belongs to a new family of putative rRNA methylases. Nucleic Acids Res 1993; 21(23):5519.

[20] Sirum-Connolly K, Mnaon TL. Functional Requirement of a Site-Specific Ribose Methylation in Ribosomal RNA. Science 1993; 262:1886-9.

[21] Yubin GE, Konard MA, Matherly LH, Taub JW. Transcriptional regulation of the human cystathionine b-synthase-1b basal promoter: synergistic transactivation by transcription factors NF-Y and Sp1/Sp3. Biochem J 2001; 357:97-105.

[22] Schumacher MA, Goodman RH, Brennan RG. The crys- tal structure of a CREB bZIP-SSCRE complex reveals the basis for selective dimerization and divalent cationenhanced DNA binding. J Biol Chem 2000; 275:352427.

[23]Swope DL, Muller CL, Chrivin JC. CREB binding protein activates transcription through multiple domains. J Biol Chem 1996; 21:28138-45.

[24] Cardinaux JR, Notis JC, Goodman RH. Recruitment of CREB Binding Protein Is Sufficient for CREB-Mediated Gene Activation. Mol Cell Biol 2000; 20(5):1546-52.

[25] Hoeffler JP, Meyer TE, Yun Y, Jameson JL, Habener JF. Cyclic-AMP-responsive DNA-binding protein: structure based on a cloned placental cDNA. Science 1988; 242: 1430-2.

[26] Mayr B, Montminy MR. Transcriptional regulation by the phosphorylation-dependent factor CREB. Nature 2001; 2:599-609.

[27] Kirby H, Rickinson A, Bell A. The activity of the EpsteinBarr virus BamHI W promoter in B cells is dependent on the binding of CREB/ATF factors. Journal of General Virology 2000; 81:1057-66.

[28] Xian LP, Gopal VK, Quinn PG. cAMP Response Element-binding Protein (CREB) Interacts with Transcription Factors IIB and IID. J Biol Chem 1995; 270:1748893.

[29] Wolffe AP, Matzke MA. Epigenetics: Regulation Through Repression. Science 1999; 286:481-6.

[30] Galvin KM, Shi Y. Multiple Mechanisms of Transcriptional Repression by YY1. Mol Cell Biol 1997; 17(7): 3723-32.

[31] Usheva A, Shenk T. YY1 transcriptional initiator: Protein interactions and association with a DNA site containing unpaired stands. Proc Natl Acad Sci USA 1996; 93:13571-6

[32] Thomas MJ, Seto E. Unlocking the mechanisms of transcription factor YY1: are chromatin modifying enzymes the key? Gene 1999; 236:197-208.

[33] Zhou QJ, Gedrich RW, Engel DA. Transcriptional Repression of the c-fos Gene by YY1 Is Mediated by a Direct Interaction with ATF/CREB. Journal of Virology 1995; 67(7): p. 4323-30.

[34] Zhou QJ, Engel DA. Adenovirus E1A243 Disrupts the ATF/CREB-YY1 Complex at the Mouse c-fos Promoter. Journal of Virology 1995; 69(12):7402-9.

[35] Yao YL, Yang WM, Seto E. Regulation of Transcription Factor YY1 by Acetylation and Deacetylation. Mol Cell Biol 2001; 21(17):5979-91. 